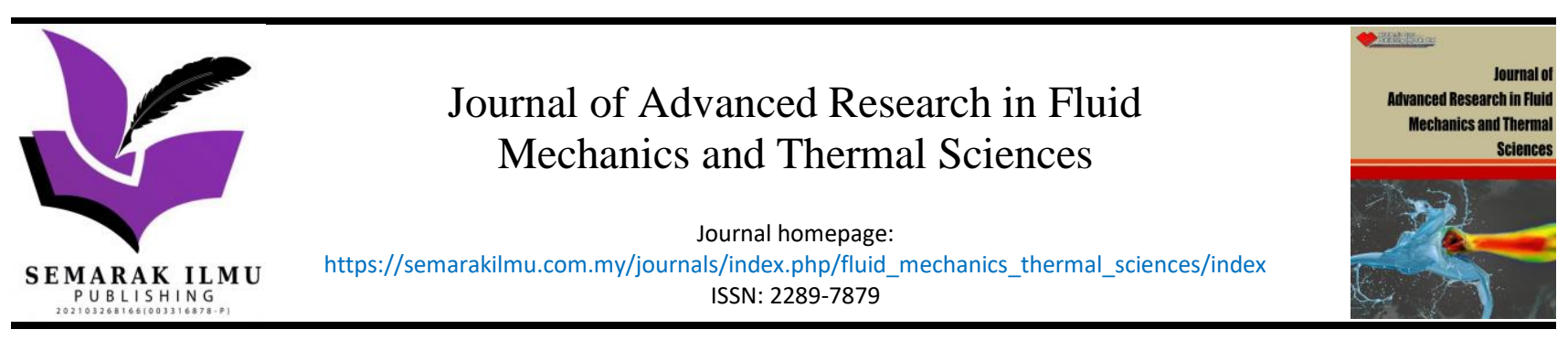

\title{
MHD Heat and Mass Transfer Steady Flow of a Convective Fluid Through a Porous Plate in The Presence of Multiple Parameters
}

\author{
Obulesu Mopuri ${ }^{1}$, Charankumar Ganteda², Bhagyashree Mahanta ${ }^{3}$, Giulio Lorenzini ${ }^{4, *}$ \\ Department of Mathematics, Siddharth Institute of Engineering and Technology, Putturu-517583, A. P., India \\ Department of Mathematics, Koneru Lakshmaiah Education Foundation, Vaddeswaram, Guntur, India \\ Department of Mathematics, Dibrugarh University, Dibrugarh-786004, Assam, India \\ University of Parma, Department of Engineering and Architecture, Parco Area delle Scienze 181/A, Parma 43124, Italy
}

\section{ARTICLE INFO}

\section{Article history:}

Received 22 July 2021

Received in revised form 6 October 2021

Accepted 25 October 2021

Available online 30 November 2021

\section{Keywords:}

MHD; thermo-diffusion; heat source or heat sink; porous medium and Joule effect

\section{ABSTRACT}

The main aim of this investigation is to study thermo diffusion, heat source/sink, Joule and chemical effects on heat transfer in MHD mixed convection flow and mass transfer past an infinite vertical plate with ohmic heating and viscous dissipation have been studied. We consider the mixed convection flow of an incompressible and electrically conducting viscous fluid such that $x^{*}$-axis is taken along the plate in upward direction and $\mathrm{y}^{*}$-axis is normal to it. A transverse constant magnetic field is applied i.e., in the direction of $\mathrm{y}^{*}$-axis. Approximate solutions have been derived for velocity, temperature, concentration profiles, skin friction, rate of heat transfer and rate of mass transfer using perturbation technique. The obtained results are discussed with the help of graphs to observe the effect of various parameters like Grashof number $(\mathrm{Gr})$, the modified Grashof number $(\mathrm{Gm})$, magnetic parameter $(\mathrm{M})$, Permeability parameter(K), Prandtl number ( $\mathrm{Pr})$, Heat Sink(Q), Radiation Parameter (F), Soret parameter (SO), Eckert number (E),Schmidt number(Sc) and Chemical reaction parameter(KO) taking two cases viz. Fluid velocity, temperature and concentration profiles are comparison with $\operatorname{Pr}=0.71$ (Air) and $\operatorname{Pr}=7$ (Water) various parameters in cooled and heated plates. Case I: when $\mathrm{Gr}>0$ (flow on cooled plate), and Case II: $\mathrm{Gr}<0$, (flow on heated plate). Both the fluid velocity and concentration rising with the increment values of Soret parameter in the fluids Air and Water and also discussed skin friction, Nusselt number and Sherwood number in the fluid's mercury, electrolytic solution, air and water. The novelty of this study is the consideration of simultaneous occurrence of radiation, heat absorption as well as thermo- diffusion in the magnetic field. It varies in several aspects such as nondimensional parameters, analytical solutions, and graphical solutions, the analytic solution using the Perturbation technique, and numerical solution using Matlab software for the profile.

\footnotetext{
* Corresponding author.

E-mail address: giulio.lorenzini@unipr.it
}

https://doi.org/10.37934/arfmts.89.2.5675 


\section{Introduction}

The prevalent process i.e., thermal diffusion, also widely known as the Soret process effect is the trend of a mixture which is convection free to get separated under a temperature gradient keeping its magnitude small. It also specifies the thermo reactive deposition or diffusion process and also the Toyota diffusion process which is a process that comprises modification of high-temperature surface that shapes a solid, skinny, wear-resilient layer of carbides, nitrides, or carbonitrides on steels as well as on other materials (which contains carbon) such as alloys of nickel and cobalt, carbides which are cemented, and carbides which are bonded by steel. In this course, the nitrogen and carbon present in the steel substrate diffuses into a deposited layer with an element which forms carbide such as vanadium, niobium, tungsten etc. It also reacts with elements which form nitride in the coating which is deposited in order to configure a non-porous, coating which is metallurgically bonded at the surface of the substrate.

With the knowledge of Soret and Dufour result, Krishna Murthy and Kumar [1] considered MHD Double Diffusive free convection process besides a perpendicular wavy surface entrenched in a doubly stratified fluid-saturated medium which is porous in nature. Umamaheswar et al., [2] scrutinized the chemical influence on MHD fluid flow which is doubly diffusive past a porous plate which is rotating in nature. Seth et al., [3] studied beautifully on MHD boundary heat and mass transfer flow on natural convection together with the effects of Soret in addition to hall current past a plate which is inclined and porous in nature with moveable suction. An intensive study on MHD fluid with visco-elastic flow bygone an infinite perpendicular plate taking in account the chemical reaction and radiation has been carried out by Raju et al., [4]. In presence of the Soret effect, Reddy et al., [5] surveyed the MHD heat generating flow in a doubly diffusive flow of convection. Chandra Reddy et al., [6] deliberately discussed the outcomes of buoyancy on chemically reactive magneto Nano fluid past a vertical plate which moves effectively. Agarwalla and Ahmed [7] studied MHD transfer of mass flow past an inclined plate in which velocity and temperature varies which is rooted in a medium (porous). An analytical study on forced convection in a channel which is partially filled with porous material which is porous taking in account of the magnetic field has been examined by Bhargavi and Reddy [8]. Sheikholeslami et al., [9] analyzed the results of Lorentz forces on NEPCM heat transfer during the solidification process in an energy storage system which porous in nature. The study on MHD boundary layer flow of a Radiative stretching cylinder and transfer of heat of a viscous incompressible fluid with thermal conductivity which vary has been discussed by Sharma and Gupta [10]. Kumar and Kumar [11] discussed the fascinating and novel characteristics of MHD convective nanofluid flow past a porous medium over a stretching sheet. A detailed study on MHD convection flow and mass transfer past a plate which is infinite, vertical and porous in nature has been carried by Kalapana and Vijaya [12]. Obulesu et al., [13] studied the Hall current effects on a convective flow of magnetohydrodynamics past a plate which is porous along with thermal radiation and absorption and chemical reaction. Raghunath et al., [14] conferred both the transfer of heat and mass on MHD flow which is unsteady past a medium (porous) between two vertical plates which is also porous in nature. MHD visco-elastic fluid flow which is double diffusive past a plate (infinite, vertical and porous) under the influence of radiation and absorption has been discussed extensively by Obulesu and Sivaprasad [15]. Raghunath et al., [16] strikingly investigated MHD second grade fluid flow over an infinite permeable plate implanted in a porosity medium. Under the influence of thermophoresis effect, hall current effects on a convective MHD flow through a plate which is porous and also with thermal radiation and chemical reaction have been discussed openly and widely by Obulesu and Prasad [17]. In presence of Ohmic heating, Reddy et al., [18] thoroughly studied the diffusion of thermal and chemical effects with simultaneous mass diffusion in a mixed convection 
flow. Goud et al., [25] studied thermal radiation and Joule heating effects on a magnetohydrodynamic Casson nanofluid flow in the presence of chemical reaction through a nonlinear inclined porous stretching sheet. Kumar et al., [26] discussed Thermal radiation impact on MHD heat transfer natural convective nano fluid flow over an impulsively started vertical plate. Goud et al., [27] studied Radiation effect on MHD boundary layer flow due to an exponentially stretching sheet. MHD viscous dissipative fluid flows in a channel with a stretching and porous plate with radiation effect has been discussed by Goud et al., [27].

There is an extensive array of appliances on the dissemination of thermal energy over mercury, solution of electrolyte, water and air in the occurrence of magnetic field, effect of chemical, absorption and thermal diffusivity. It is therefore, proposed to study in this present paper the effects of mass and heat transfer of a natural convection fluid flow through a plate which is porous in nature in the manifestation of multiple parameters. This study is an expansion work of Reddy et al., [18]. The originality of this study lies in the contemplation of instant occurrence of radiation, heat absorption as well as thermo- diffusion.

\section{Mathematical Formulation}

In the present problem, we have considered a fluid which is viscous, incompressible, electrically conducting and radiating in nature past a medium (porous) which inhabit a $\backslash$ region of the space which is semi- infinite and bounded by a surface which is also vertical and infinite. Along the surface is the $x$ - axis which is in an upward direction and the axis which is normal to it is the $y$ - axis. In the direction of the latter axis, a transverse effect is imposed by the strength of uniform magnetic field $\left(B_{0}\right)$ in addition to radiation and Joule heating. The fluid properties are presumed to be stable keeping its density excluded in the term which includes the body force. Additionally, species which are chemically reactive is assumed to be secreted from the surface (vertical) into a field whose flow is hydrodynamic and that it diffuses into the fluid, where it experiences a reaction which is chemically homogenous. The reaction is presumed to take place throughout in the stream. Conclusively, the flow that is developed past a medium which is supposed to be highly porous is presided by the equations given below:

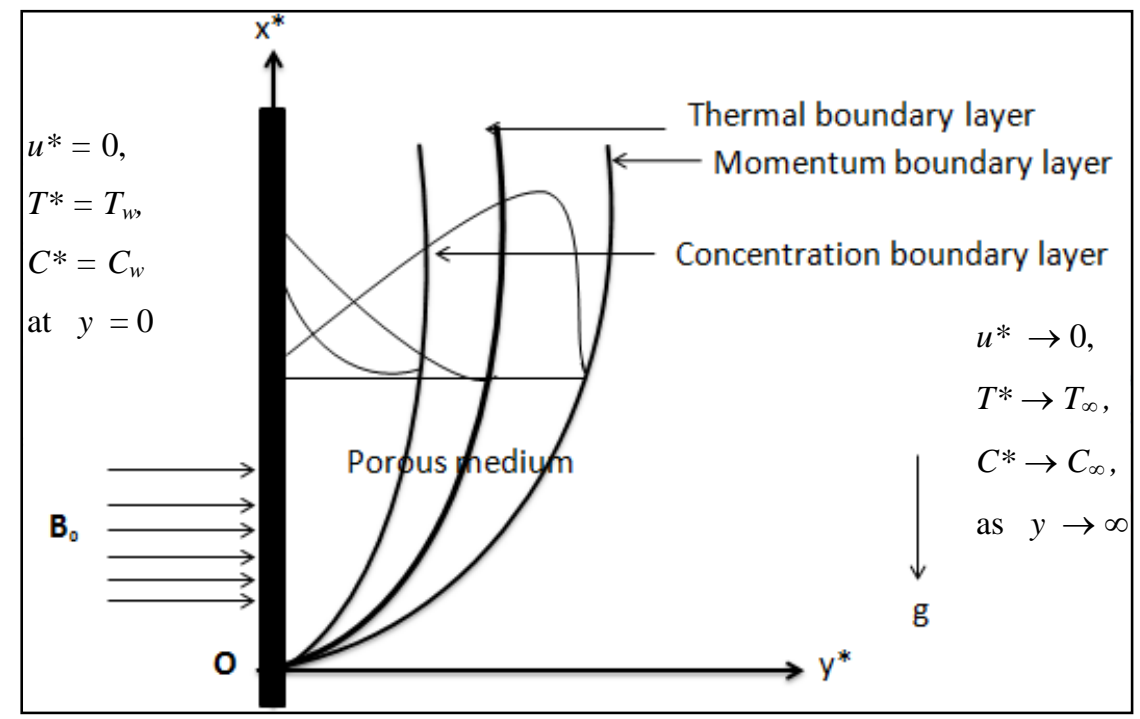

Fig. 1. Physical model of the problem 
Basic Equations: The equations governing the flow of a viscous incompressible and electrically conducting fluid in the presence of magnetic field are

Equation of continuity:

$\bar{\nabla} \cdot \bar{q}=0$

Momentum equation:

$\rho[(\bar{q} \cdot \bar{\nabla}) \bar{q}]=-\bar{\nabla} p+\bar{J} \times \bar{B}+\rho \bar{g}+\mu \nabla^{2} \bar{q}-\left[\frac{\mu}{k^{*}}\right] \bar{q}$

Ohm's law:

$\bar{J}=\sigma[\bar{E}+(\bar{q} \times \bar{B})]$

Gauss' law of magnetism:

$\bar{\nabla} \cdot \bar{B}=0$

Energy equation:

$\rho C_{p}\left[(\bar{q} \cdot \bar{\nabla}) T^{*}\right]=K \nabla^{2} T^{*}+\mu(\nabla \cdot \bar{q})^{2}-\nabla q_{r}^{*}+\mu \nabla^{2} \bar{q}^{2}-Q^{*}\left(T^{*}-T_{\infty}^{*}\right)$

Species continuity equation:

$(\bar{q} \cdot \bar{\nabla}) C^{*}=D_{M} \nabla^{2} C^{*}+K^{*}\left(C_{\infty}^{*}-C^{*}\right)+\frac{D_{M} K_{T}}{T_{M}} \nabla^{2} T^{*}$

Based on the above basic equations the following derived mathematical formulation has been done.

$$
\begin{aligned}
& \frac{\partial v^{\prime}}{\partial y^{\prime}}=0 \\
& v^{\prime} \frac{\partial u^{\prime}}{\partial y^{\prime}}=\vartheta \frac{\partial^{2} u^{\prime}}{\partial y^{\prime 2}}+g \beta_{T}\left(T^{\prime}-T_{\infty}^{\prime}\right)+g \beta_{C}\left(C^{\prime}-C_{\infty}^{\prime}\right)-\frac{\sigma B_{0}^{2}}{\rho} u^{\prime}-\vartheta \frac{u^{\prime}}{K_{P}} \\
& v^{\prime} \frac{\partial T^{\prime}}{\partial y^{\prime}}=\frac{K}{\rho C_{p}} \frac{\partial^{2} T^{\prime}}{\partial y^{\prime 2}}+\frac{\vartheta}{C_{p}}\left(\frac{\partial u^{\prime}}{\partial y^{\prime}}\right)^{2}-\frac{1}{\rho C_{p}} \frac{\partial q_{r}^{\prime}}{\partial y^{\prime}}+\frac{\sigma B_{0}^{2}}{\rho C_{P}} u^{\prime 2}-\frac{Q_{1}}{\rho C_{p}}\left(T^{\prime}-T_{\infty}^{\prime}\right) \\
& v^{\prime} \frac{\partial C^{\prime}}{\partial y^{\prime}}=D \frac{\partial^{2} C^{\prime}}{\partial y^{\prime 2}}-K_{C}\left(C^{\prime}-C_{\infty}^{\prime}\right)+D_{1} \frac{\partial^{2} T^{\prime}}{\partial y^{\prime 2}}
\end{aligned}
$$

The relevant boundary conditions are given as follows 


$$
\begin{array}{lll}
u^{\prime}=0 & T^{\prime}=T_{w}, & C^{\prime}=C_{w} \text { at } y^{\prime}=0 \\
u^{\prime} \rightarrow 0 & T^{\prime} \rightarrow T_{\infty}, & C^{\prime} \rightarrow C_{\infty} \text { as } y^{\prime} \rightarrow \infty
\end{array}
$$

Eq. (1) gives that $v^{\prime}=$ const. $=-v_{0}\left(v_{0}>0\right)$

In the optically thick limit, the fluid tends not absorb its own radiation which they emit as there is no self-absorption. In other words, they absorb radiation emitted by the boundaries. Cogley et al., [19] showed the similar approach as above, for a non-gray gas near equilibrium as given below.

$$
\frac{\partial q_{r}}{\partial y^{\prime}}=4\left(T^{\prime}-T_{\infty}^{\prime}\right) \int_{0}^{\infty} K_{\lambda w} \frac{d e_{b \lambda}}{d T^{\prime}} d \lambda=4 I_{1}\left(T^{\prime}-T_{\infty}^{\prime}\right)
$$

We introduce the quantities (non-dimensional) as follows,

$$
\begin{aligned}
& u=\frac{u^{\prime}}{v_{0}}, y=\frac{v_{0} y^{\prime}}{\vartheta}, \theta=\frac{T^{\prime}-T_{\infty}^{\prime}}{T_{w}-T_{\infty}^{\prime}}, \phi=\frac{C^{\prime}-C_{\infty}^{\prime}}{C_{w}-C_{\infty}^{\prime}}, \operatorname{Pr}=\frac{\mu C_{p}}{K}, S c=\frac{\vartheta}{D}, M=\frac{\sigma B_{0}^{2} \vartheta}{\rho v_{0}^{2}}, \\
& G r=\frac{\vartheta g \beta_{T}\left(T_{w}-T_{\infty}^{\prime}\right)}{v_{0}^{3}}, G m=\frac{\vartheta g \beta_{C}\left(C_{w}-C_{\infty}^{\prime}\right)}{v_{0}^{3}}, E=\frac{v_{0}^{2}}{C_{P}\left(T_{w}-T_{\infty}^{\prime}\right)}, K=\frac{v_{0}^{2} K_{P}}{\vartheta^{2}} \\
& K_{0}=\frac{\vartheta K_{C}}{v_{0}^{2}}, F=\frac{4 I_{1} \vartheta^{2}}{K v_{0}^{2}}, Q=\frac{Q_{1} v^{2}}{K v_{0}^{2}}, S_{0}=\frac{D_{1}\left(T_{w}-T_{\infty}^{\prime}\right)}{\vartheta\left(C_{w}-C_{\infty}^{\prime}\right)}
\end{aligned}
$$

The governing Eq. (2)-(4) which are in the form of non-dimensional trims down to

$$
\begin{aligned}
& u^{\prime \prime}+u^{\prime}=-\mathrm{Gr} \theta-\mathrm{Gm} \phi+\mathrm{M}_{1} \mathrm{u} \\
& \theta^{\prime \prime}+\operatorname{Pr} \theta^{\prime}-(\mathrm{F}+\mathrm{Q}) \theta=-\operatorname{Pr} u^{1^{2}}-\operatorname{PrM} u^{2} \\
& \phi^{\prime \prime}+\operatorname{Sc} \phi^{\prime}-\mathrm{ScK}_{0} \phi=-\mathrm{S}_{0} \mathrm{Sc} \theta^{\prime \prime}
\end{aligned}
$$

Where $M_{1}=M+1 / K$.

The analogous boundary conditions are set by

$$
\begin{aligned}
& u=0, \quad \theta=1, \quad \phi=1 \quad \text { at } y=0 \\
& u \rightarrow 0, \quad \theta \rightarrow 0, \quad \phi \rightarrow 0 \quad \text { as } y \rightarrow \infty
\end{aligned}
$$

\section{Solution of the Problem}

In this study simple perturbation method is used to solve the coupled nonlinear system Eq. (9)(11) together with the help of boundary conditions (12). The governing Eq. (9)-(11) are then expanded in terms of powers of $E$ which is significantly very small. 


$$
\begin{aligned}
& u=u_{0}+E u_{1}+O\left(E^{2}\right), \\
& \theta=\theta_{0}+E \theta_{1}+O\left(E^{2}\right), \\
& \phi=\phi_{0}+E \phi_{1}+O\left(E^{2}\right)
\end{aligned}
$$

Substituting the Eq. (13) to Eq. (9)-(11) and expanding the same way keeping the higher orders of E neglected, the following equations are achieved.

Zero order terms:

$$
\begin{aligned}
& u_{0}^{\prime \prime}+u_{0}^{\prime}=-\mathrm{Gr} \theta_{0}-\mathrm{Gm} \phi_{0}+\mathrm{M}_{1} \mathrm{u}_{0} \\
& \theta_{0}^{\prime \prime}+\operatorname{Pr} \theta_{0}^{\prime}-(\mathrm{F}+\mathrm{Q}) \theta_{0}=0 \\
& \phi_{0}^{\prime \prime}+\operatorname{Sc} \phi_{0}^{\prime}-\mathrm{ScK}_{0} \phi_{0}=-\mathrm{S}_{0} \operatorname{Sc} \theta_{0}^{\prime \prime}
\end{aligned}
$$

First order terms:

$$
\begin{aligned}
& u_{1}^{\prime \prime}+u_{1}^{\prime}=-\mathrm{Gr} \theta_{1}-\mathrm{Gm} \phi_{1}+\mathrm{M}_{1} \mathrm{u}_{1} \\
& \theta_{1}^{\prime \prime}+\operatorname{Pr} \theta_{1}^{\prime}-(\mathrm{F}+\mathrm{Q}) \theta_{1}=-\operatorname{Pru}_{0}^{1^{2}}-\operatorname{PrM} u_{0}^{2} \\
& \phi_{1}^{\prime \prime}+S c \phi_{1}^{\prime}-S c K_{0} \phi_{1}=-S_{0} S c \theta_{1}^{\prime \prime}
\end{aligned}
$$

The corresponding boundary conditions are

$$
\begin{aligned}
& u_{0}=0, \quad u_{1}=0, \quad \theta_{0}=1, \quad \theta_{1}=0, \quad \phi_{0}=1, \phi_{1}=0 \quad \text { at } y=0 \\
& u_{0} \rightarrow 0, u_{1} \rightarrow 0, \quad \theta_{0} \rightarrow 1, \theta_{1} \rightarrow 0, \quad \phi_{0} \rightarrow 1, \phi_{1} \rightarrow 0 \quad \text { as } y=\infty
\end{aligned}
$$

Solving the Eq. (14)-(19) under the boundary conditions set in Eq. (20), the following solutions are obtained

$$
\begin{aligned}
\theta_{0}= & e^{-m_{1} y} \\
\phi_{0}= & -A_{1} e^{-m_{1} y}+A_{2} e^{-m_{2} y} \\
u_{0}= & A_{3} e^{-m_{1} y}-A_{4} e^{-m_{2} y}+A_{5} e^{-m_{3} y} \\
\theta_{1}= & A_{18} e^{-2 m_{1} y}+A_{19} e^{-2 m_{2} y}+A_{20} e^{-2 m_{3} y}+A_{21} e^{-\delta_{1} y}+A_{22} e^{-\delta_{2} y} \\
& +A_{23} e^{-\delta_{3} y}+A_{24} e^{-m_{1} y} \\
\phi_{1}= & A_{25} e^{-m_{1} y}+A_{26} e^{-2 m_{1} y}+A_{27} e^{-2 m_{2} y}+A_{28} e^{-2 m_{3} y}+A_{29} e^{-\delta_{1} y}+A_{30} e^{-\delta_{2} y} \\
& +A_{31} e^{-\delta_{3} y}+A_{32} e^{-m_{2} y}
\end{aligned}
$$




$$
\begin{aligned}
u_{1}= & A_{33} e^{-m_{1} y}+A_{34} e^{-m_{2} y}+A_{35} e^{-2 m_{1} y}+A_{36} e^{-2 m_{2} y}+A_{37} e^{-2 m_{3} y}+A_{38} e^{-\delta_{1} y}+A_{39} e^{-\delta_{2} y} \\
& +A_{40} e^{-\delta_{3} y}+A_{41} e^{-m_{3} y}
\end{aligned}
$$

Substituting Eq. (21)-(26) in Eq. (13) we obtain the velocity, temperature and concentration field as given below

$$
\begin{aligned}
u= & A_{3} e^{-m_{1} y}-A_{4} e^{-m_{2} y}+A_{5} e^{-m_{3} y}+E\left[A_{33} e^{-m_{1} y}+A_{34} e^{-m_{2} y}+A_{35} e^{-2 m_{1} y}\right. \\
& \left.+A_{36} e^{-2 m_{2} y}+A_{37} e^{-2 m_{3} y}+A_{38} e^{-\delta_{1} y}+A_{39} e^{-\delta_{2} y}+A_{40} e^{-\delta_{3} y}+A_{41} e^{-m_{3} y}\right] \\
\theta= & e^{-m_{1} y}+E\left[A_{18} e^{-2 m_{1} y}+A_{19} e^{-2 m_{2} y}+A_{20} e^{-2 m_{3} y}+A_{21} e^{-\delta_{1} y}+A_{22} e^{-\delta_{2} y}\right. \\
& \left.+A_{23} e^{-\delta_{3} y}+A_{24} e^{-m_{1} y}\right] \\
\phi= & -A_{1} e^{-m_{1} y}+A_{2} e^{-m_{2} y}+E\left[A_{25} e^{-m_{1} y}+A_{26} e^{-2 m_{1} y}+A_{27} e^{-2 m_{2} y}\right. \\
& \left.+A_{28} e^{-2 m_{3} y}+A_{29} e^{-\delta_{1} y}+A_{30} e^{-\delta_{2} y}+A_{31} e^{-\delta_{3} y}+A_{32} e^{-m_{2} y}\right]
\end{aligned}
$$

\section{Skin Friction:}

At the surface the skin friction (non- dimensional) is given by

$$
\begin{aligned}
\tau= & \left(\frac{\partial u}{\partial y}\right)_{y=0} \\
\tau= & {\left[-m_{3} A_{5}+m_{2} A_{4}-m_{1} A_{3}\right] } \\
& +E\left[m_{1} A_{33}-m_{2} A_{34}-2 m_{1} A_{35}-2 m_{2} A_{36}-2 m_{3} A_{37}-\delta_{1} A_{38}-\delta_{2} A_{39}-\delta_{3} A_{40}-m_{3} A_{41}\right]
\end{aligned}
$$

\section{Nusselt Number:}

At the surface, in terms of Nusselt number the rate of heat transfer is given by

$$
\begin{aligned}
& N u=-\left(\frac{\partial \theta}{\partial y}\right)_{y=0} \\
& N u=m_{1}+E\left[m_{1} A_{24}+2 m_{1} A_{18}+2 m_{2} A_{19}+2 m_{3} A_{20}+\delta_{1} A_{21}+\delta_{2} A_{22}+\delta_{3} A_{23}\right]
\end{aligned}
$$

\section{Sherwood Number:}

At the wall, in terms of Sherwood number the rate of mass transfer is given by

$$
S h=-\left(\frac{\partial \phi}{\partial y}\right)_{y=0}
$$




$$
\begin{aligned}
S h= & {\left[m_{2} A_{2}-m_{1} A_{1}\right] } \\
& +E\left[m_{1} A_{25}+2 m_{1} A_{26}+2 m_{2} A_{27}+2 m_{3} A_{28}+\delta_{1} A_{29}+\delta_{2} A_{30}+\delta_{3} A_{31}+m_{2} A_{32}\right]
\end{aligned}
$$

\section{Results and Discussion}

An imperial study in velocity, temperature and concentration field pertaining to the effects of the mixed MHD convection flow on both mass and heat transfer of a fluid (viscous, incompressible, conducting) past a vertical plate (infinite and porous) in addition of magnetic field, radiation, absorption and chemical effects has been done extensively in the preceding sections. The numerical figures are portrayed for two cases of Gr during cooling and heating of the plate. The values of Prandtl number (Pr) are taken as 1, 0.025, 0.71 and 7, which represents electrolytic friction, Mercury, Air, Water, heat and mass transfer respectively. The mercury level is taken as the reading of $20^{\circ} \mathrm{C}$ temperature and 1 atmosphere pressure and the value of Eckert number is taken as 0.02 . The values of Sc are taken to be $0.22,0.30,0.60$ and 0.78 which represents for hydrogen, helium, water vapour and ammonia respectively. Some other values such as $\mathrm{Gr}=5, \mathrm{Gm}=5, \mathrm{~K}=1, \mathrm{~K}_{0}=1, \mathrm{M}=2, \mathrm{~F}=1, \mathrm{Q}=1$ are also taken into consideration. The obtained results are elucidated and explained in Figure 2 to Figure 23.

In order to reveal the influences of various parameters on the three profiles (i.e., velocity, temperature and concentration) through Figure 2 to Figure 23 study and efforts have been done by choosing various arbitrary values of the parameters. The influences of these parameters on skin friction, Nusselt number and Sherwood number are also shown in Table 1 to Table 3.

From Figure 2 to Figure 23 depict the velocity, temperature and concentration profiles for fluid flow on cooled and heated plates respectively.

Effect of $\mathrm{M}$ and Sc are shown in Figure 2 to Figure 5 on fluid velocity for $\mathrm{Pr}=0.71$ and $\mathrm{Pr}=7$. We observe that the velocity gradient at the surface decreases with the enhancement of magnetic parameter and Schmidt number. An opposite phenomenon is noted in the case of cooled and heated plates, from Figure 6 to Figure 11 shows the effect of $\mathrm{K}, \mathrm{Gm}$ and $\mathrm{S}_{0}$ for fluid velocity for $\mathrm{Pr}=0.71$ and $\mathrm{Pr}=7$ respectively. We observed that there is an upsurge in fluid velocity for increasing values of $\mathrm{K}$, Gm and So.

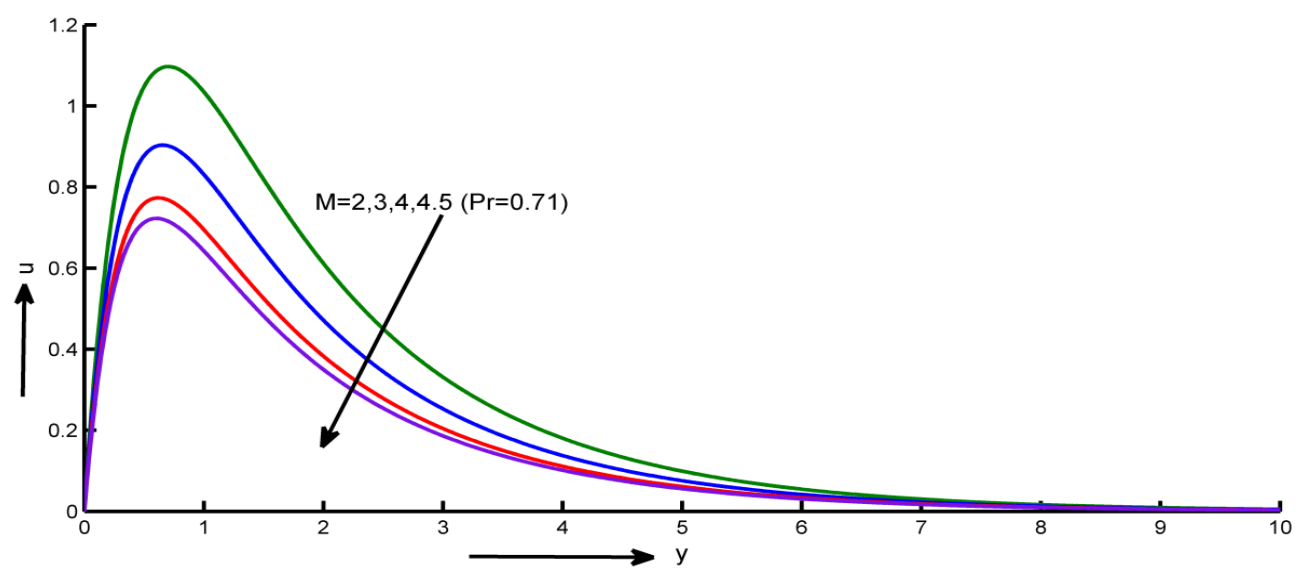

Fig. 2. Velocity profile for $\mathrm{Gr}=5.0\left(\mathrm{Sc}=0.22, \mathrm{Gm}=5, \mathrm{~K}=1, \mathrm{~K}_{0}=1, \mathrm{~F}=1, \mathrm{Q}=1\right.$ and $\left.\mathrm{S}_{0}=1\right)$ 


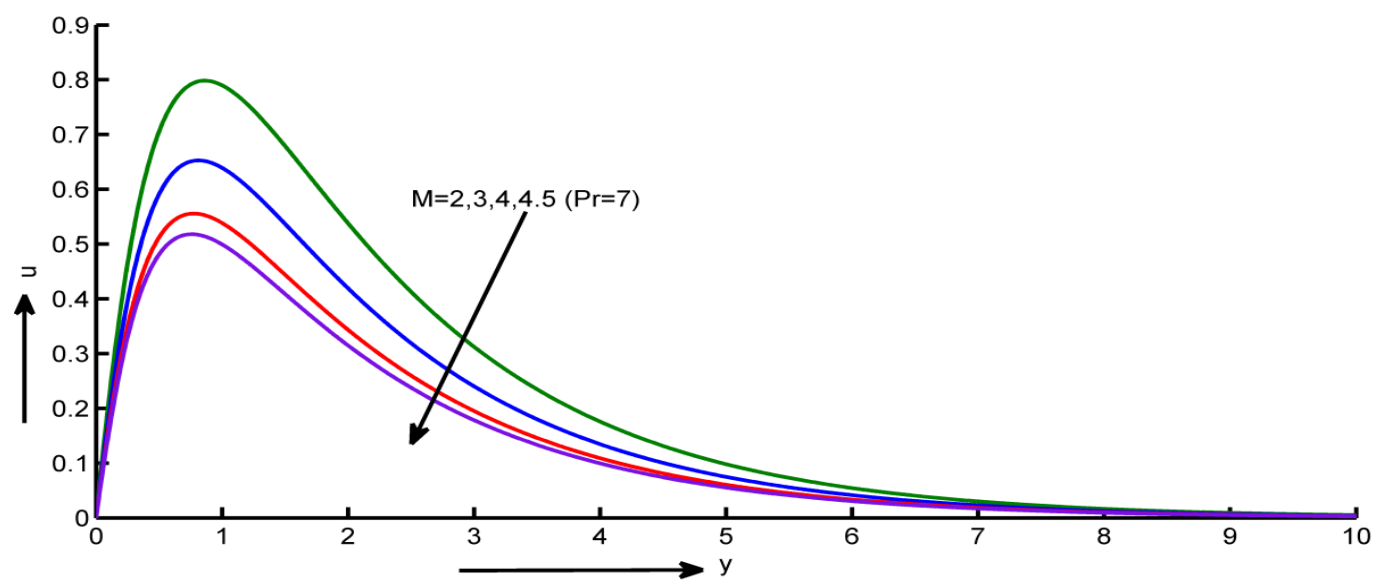

Fig. 3. Velocity profile for $\mathrm{Gr}=-5.0\left(\mathrm{Sc}=0.22, \mathrm{Gm}=5, \mathrm{~K}=1, \mathrm{~K}_{0}=1, \mathrm{~F}=1, \mathrm{Q}=1\right.$ and $\left.\mathrm{S}_{0}=1\right)$

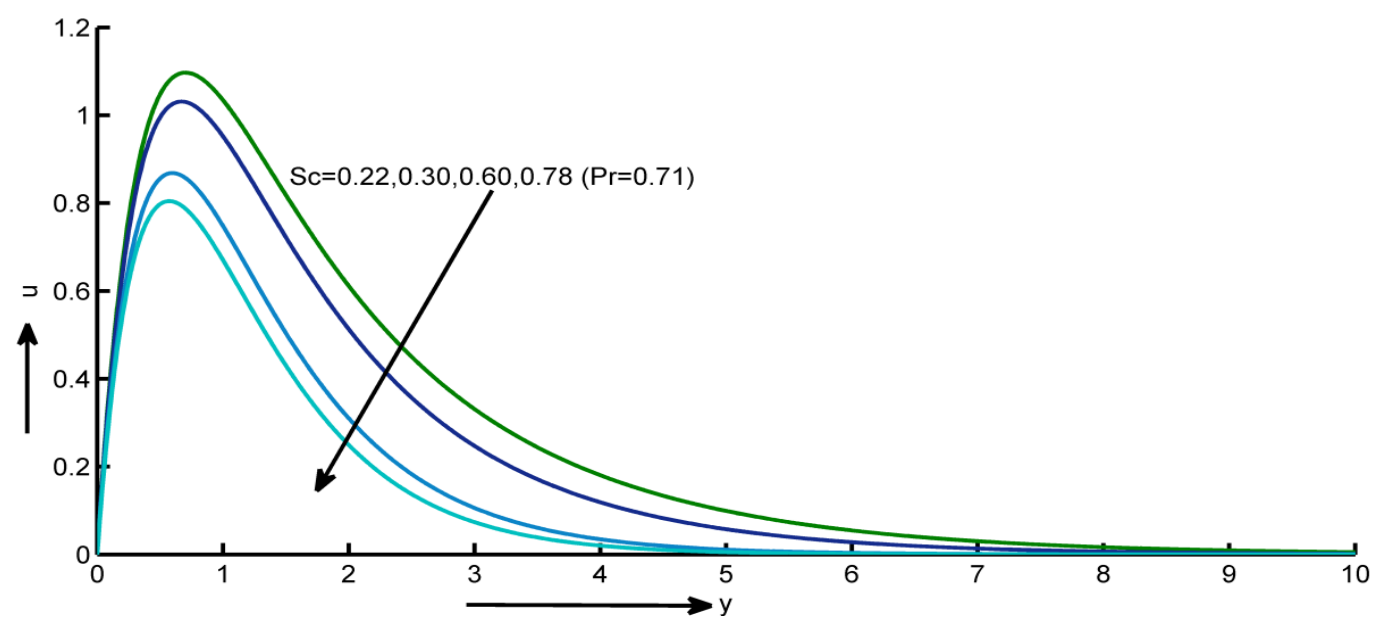

Fig. 4. Velocity profile for $\mathrm{Gr}=5.0\left(\mathrm{Gm}=5, \mathrm{~K}=1, \mathrm{M}=2, \mathrm{~K}_{0}=1, \mathrm{~F}=1, \mathrm{Q}=1\right.$ and $\left.\mathrm{S}_{0}=1\right)$

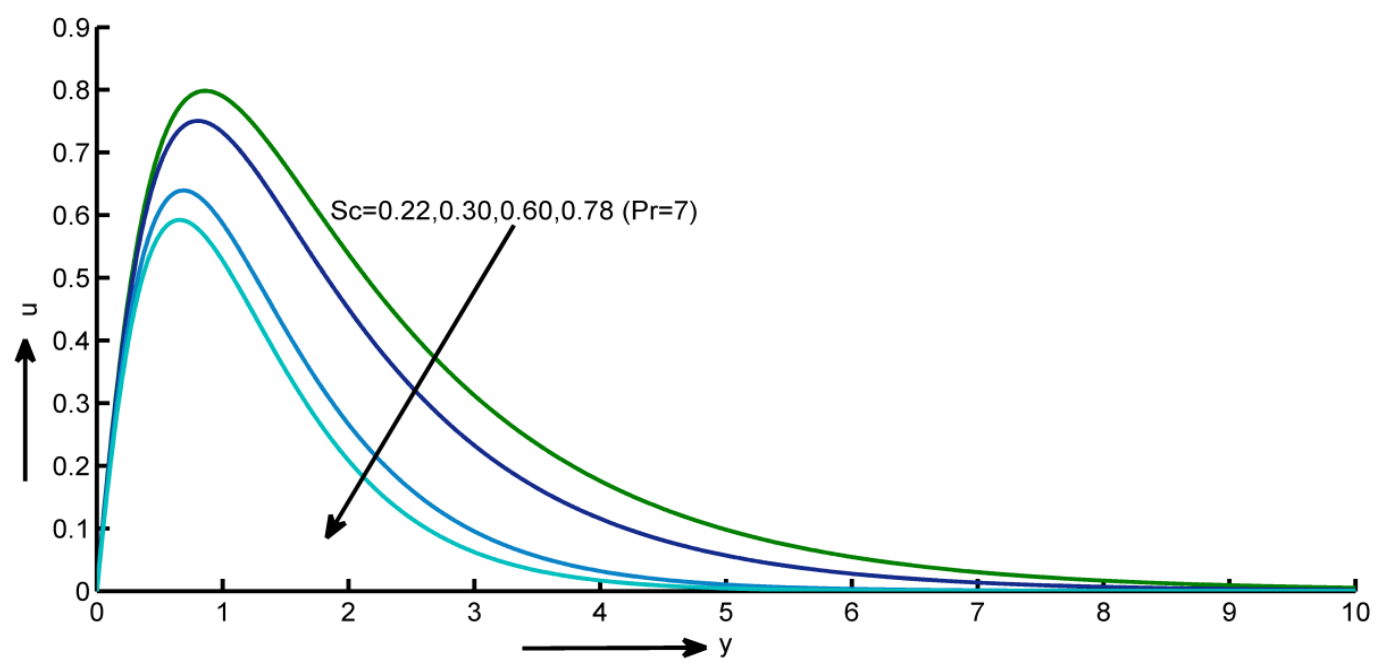

Fig. 5. Velocity profile for $\mathrm{Gr}=-5.0\left(\mathrm{Gm}=5, \mathrm{~K}=1, \mathrm{M}=2, \mathrm{~K}_{0}=1, \mathrm{~F}=1, \mathrm{Q}=1\right.$ and $\left.\mathrm{S}_{0}=1\right)$ 


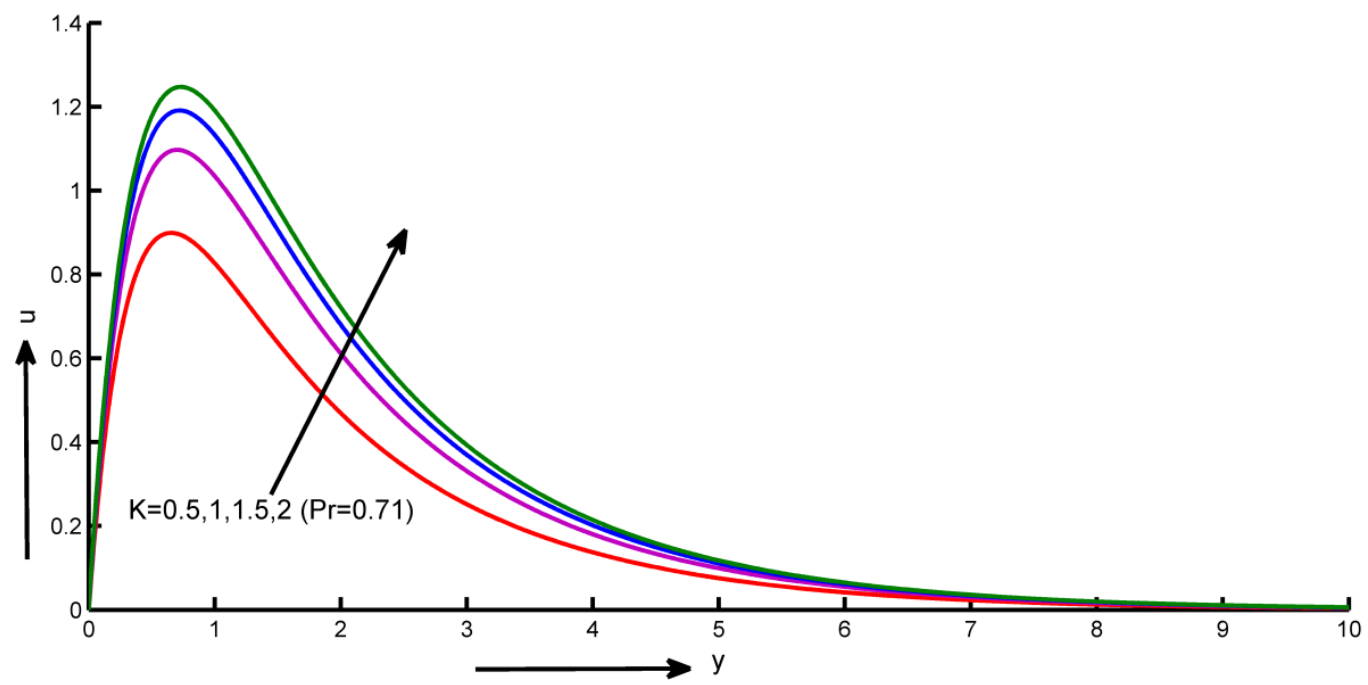

Fig. 6. Velocity profile for $\mathrm{Gr}=5.0\left(\mathrm{Sc}=0.22, \mathrm{Gm}=5, \mathrm{M}=2, \mathrm{~K}_{0}=1, \mathrm{~F}=1, \mathrm{Q}=1\right.$ and $\left.\mathrm{S}_{0}=1\right)$

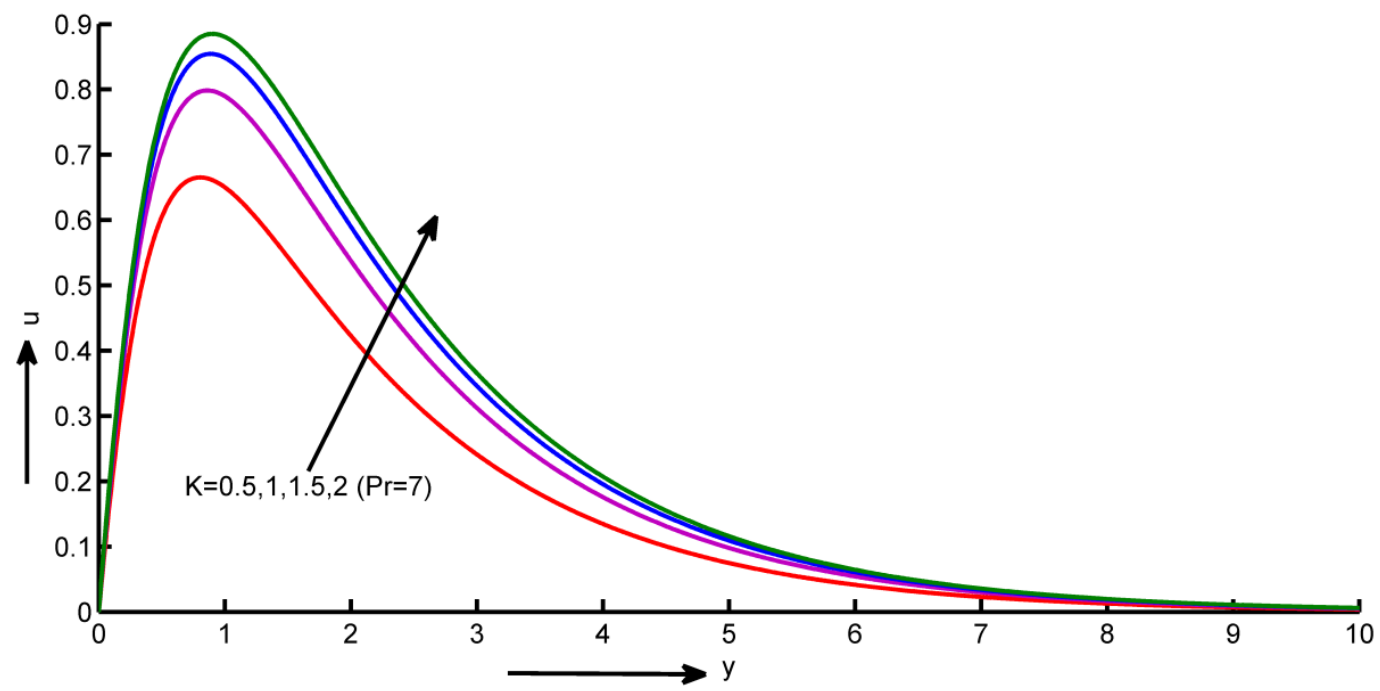

Fig. 7. Velocity profile for $\mathrm{Gr}=-5.0\left(\mathrm{Sc}=0.22, \mathrm{Gm}=5, \mathrm{M}=2, \mathrm{~K}_{0}=1, \mathrm{~F}=1, \mathrm{Q}=1\right.$ and $\left.\mathrm{S}_{0}=1\right)$

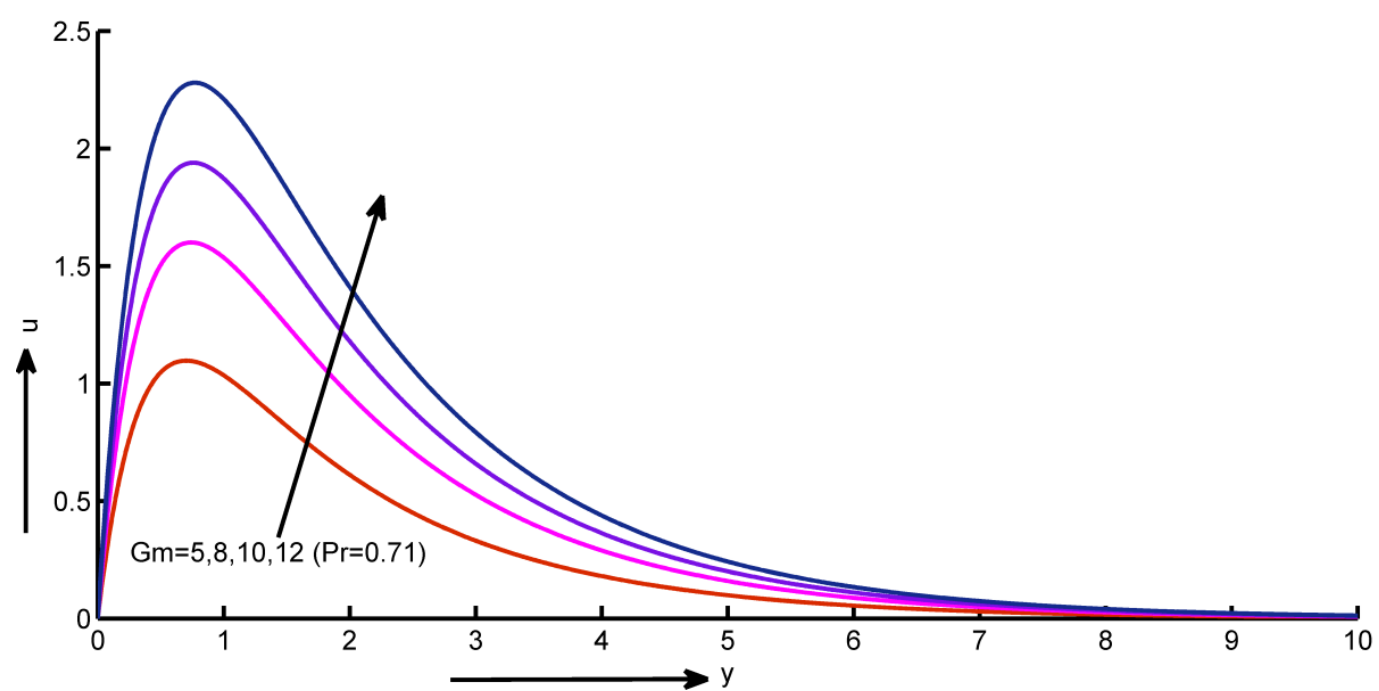

Fig. 8. Velocity profile for $\mathrm{Gr}=5.0\left(\mathrm{Sc}=0.22, \mathrm{~K}=1, \mathrm{M}=2, \mathrm{~K}_{0}=1, \mathrm{~F}=1, \mathrm{Q}=1\right.$ and $\left.\mathrm{S}_{0}=1\right)$ 


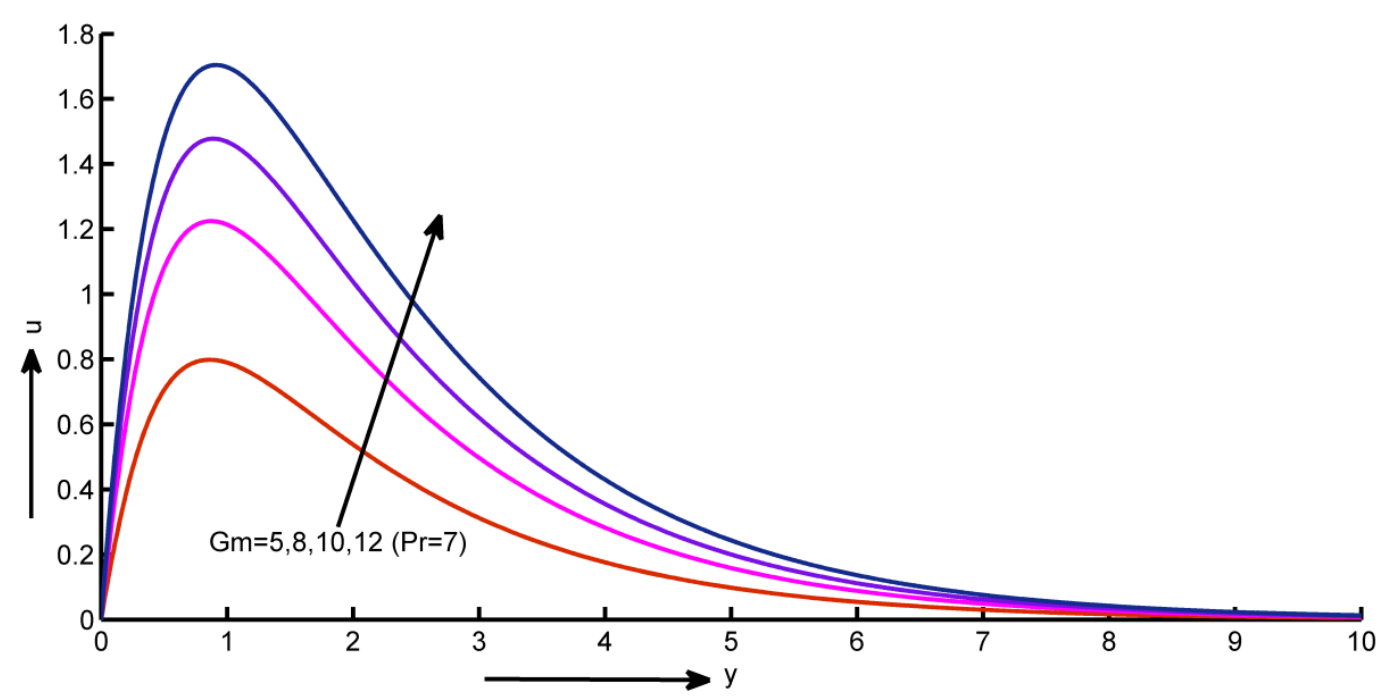

Fig. 9. Velocity profile for $\mathrm{Gr}=-5.0\left(\mathrm{Sc}=0.22, \mathrm{~K}=1, \mathrm{M}=2, \mathrm{~K}_{0}=1, \mathrm{~F}=1, \mathrm{Q}=1\right.$ and $\left.\mathrm{S}_{0}=1\right)$

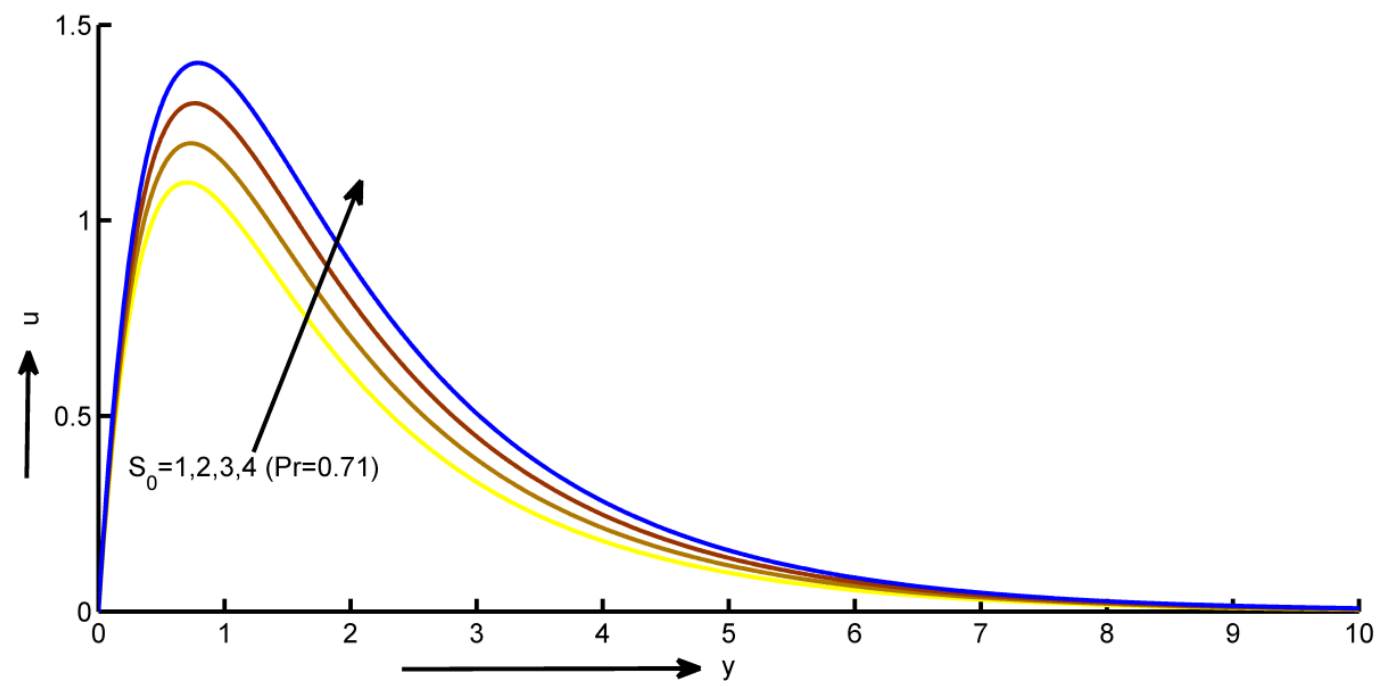

Fig. 10. Velocity profile for $\mathrm{Gr}=5.0\left(\mathrm{Gm}=5, \mathrm{~K}=1, \mathrm{M}=2, \mathrm{~K}_{0}=1, \mathrm{~F}=1, \mathrm{Q}=1\right.$ and $\left.\mathrm{Sc}=0.22\right)$

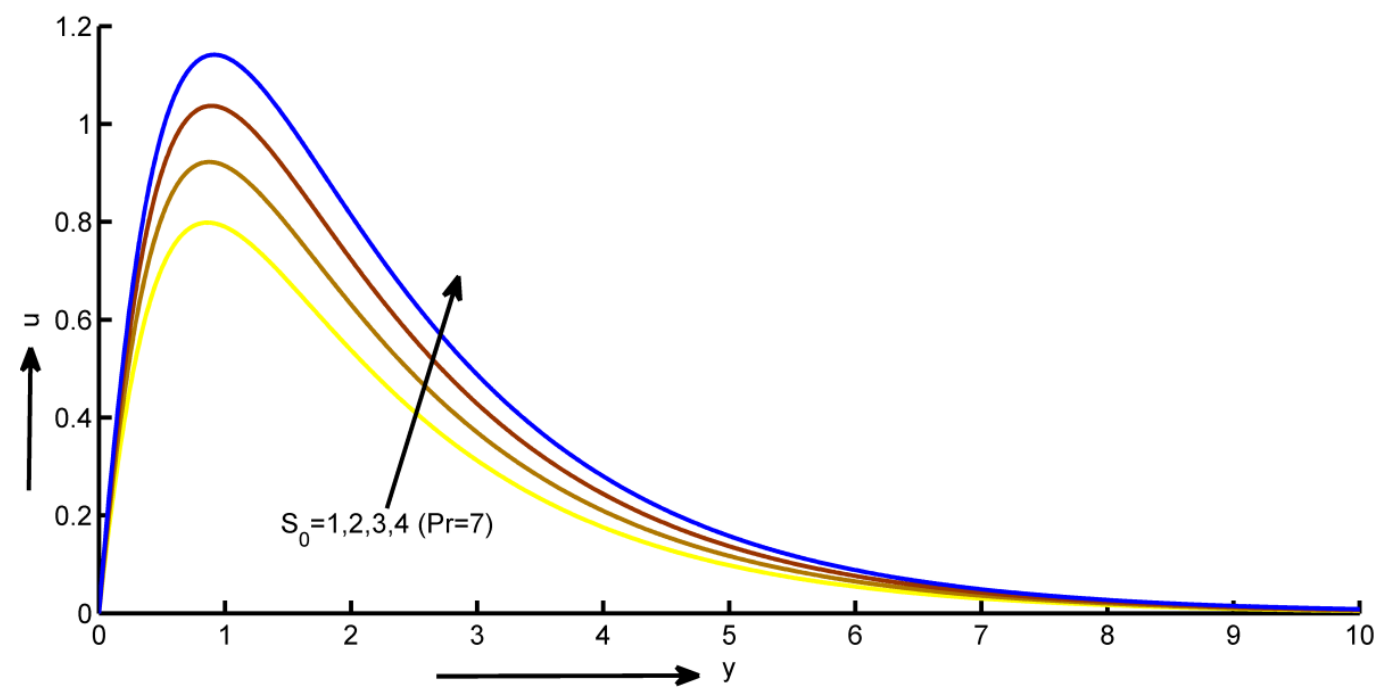

Fig. 11. Velocity profile for $\mathrm{Gr}=-5.0\left(\mathrm{Gm}=5, \mathrm{~K}=1, \mathrm{M}=2, \mathrm{~K}_{0}=1, \mathrm{~F}=1, \mathrm{Q}=1\right.$ and $\left.\mathrm{Sc}=0.22\right)$ 
In Figure 12 to Figure 17, the effects of $\mathrm{Pr}, \mathrm{F}$ and $\mathrm{Q}$ on temperature profiles are shown graphically for $\mathrm{Gr}=5$ and $\mathrm{Gr}=-5$. It is perceived that for the plates, if there is a rise in the Prandtl number, radiation parameter and heat absorption parameter, a fall in the temperature for $\operatorname{Pr}=0.71$ and $\operatorname{Pr}=7$ is noted. The reason lies in the fact that with the increase of the said parameters there is a decrease in the thickness of thermal boundary layer.

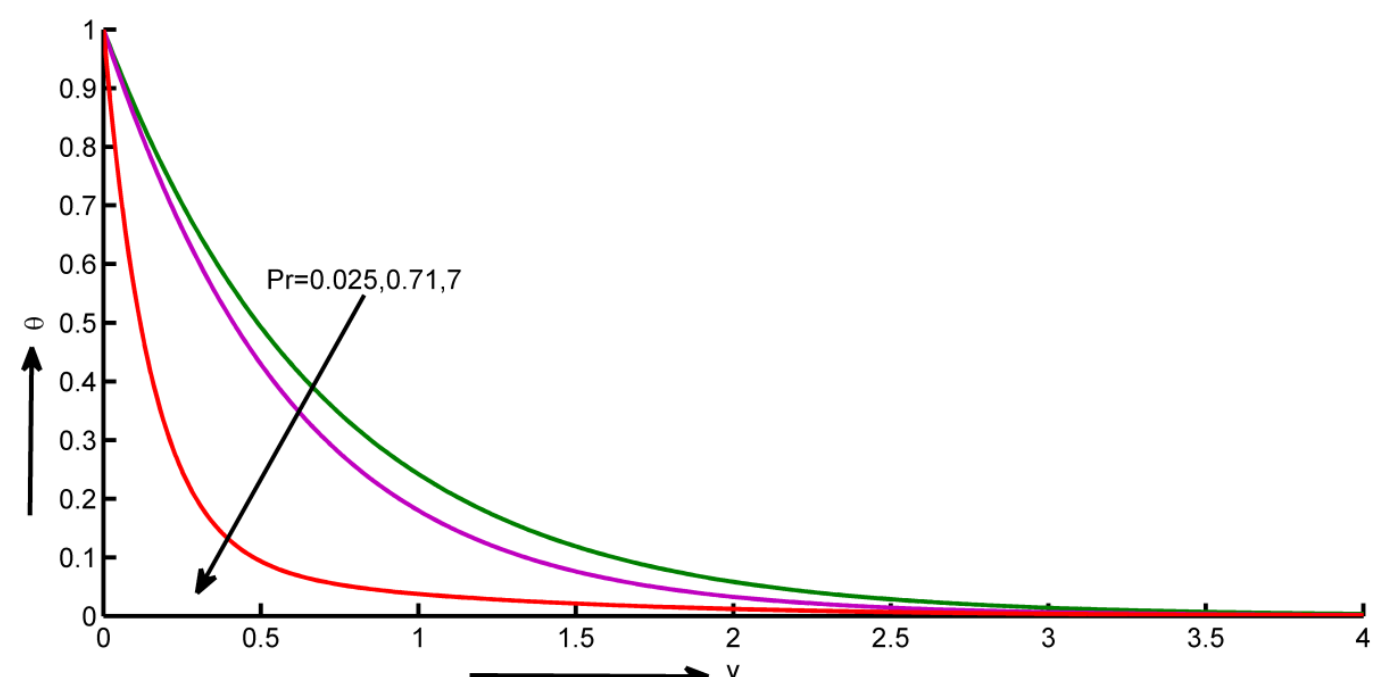

Fig. 12. Temperature profile for $\mathrm{Gr}=5.0\left(\mathrm{Gm}=5, \mathrm{~K}=1, \mathrm{M}=2, \mathrm{~K}_{0}=1, \mathrm{~F}=1, \mathrm{Q}=1, \mathrm{So}=1\right.$ and $\mathrm{Sc}=0.22$ )

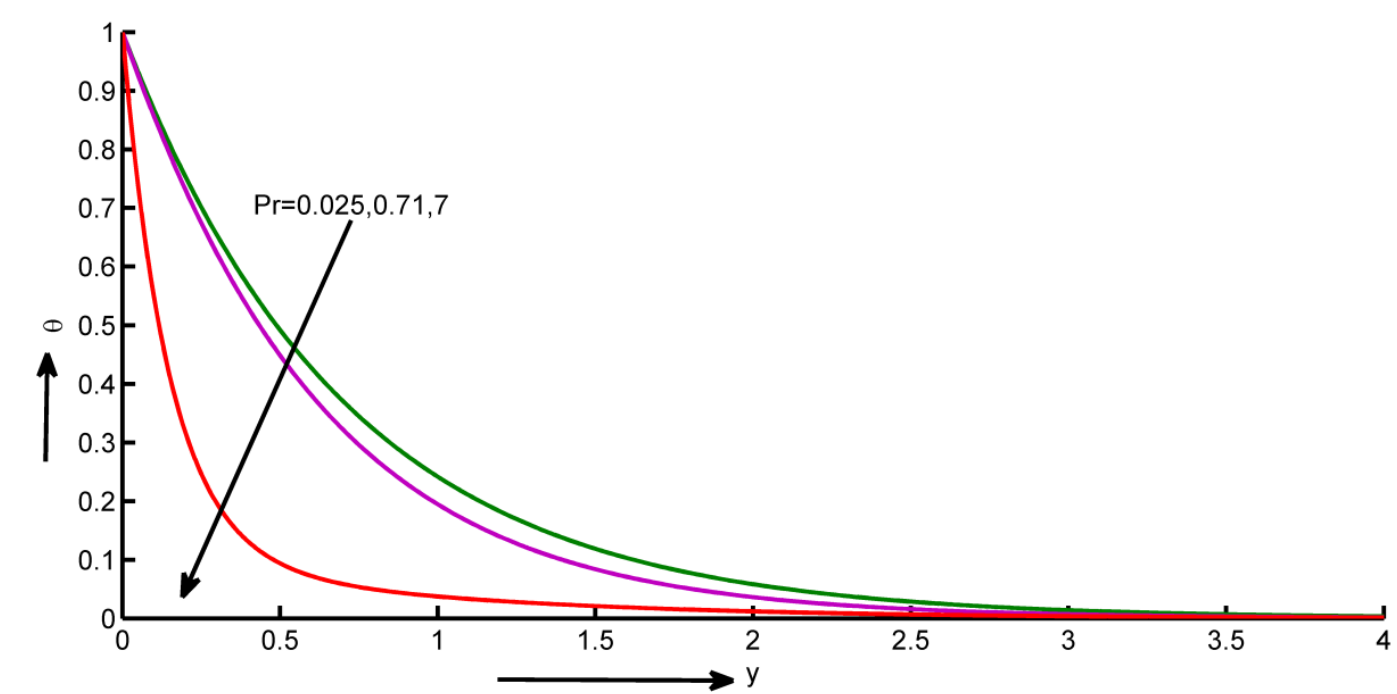

Fig. 13. Temperature profile for $\mathrm{Gr}=-5.0\left(\mathrm{Gm}=5, \mathrm{~K}=1, \mathrm{M}=2, \mathrm{~K}_{0}=1, \mathrm{~F}=1, \mathrm{Q}=1, \mathrm{~S}_{0}=1\right.$ and $\mathrm{Sc}=0.22$ ) 


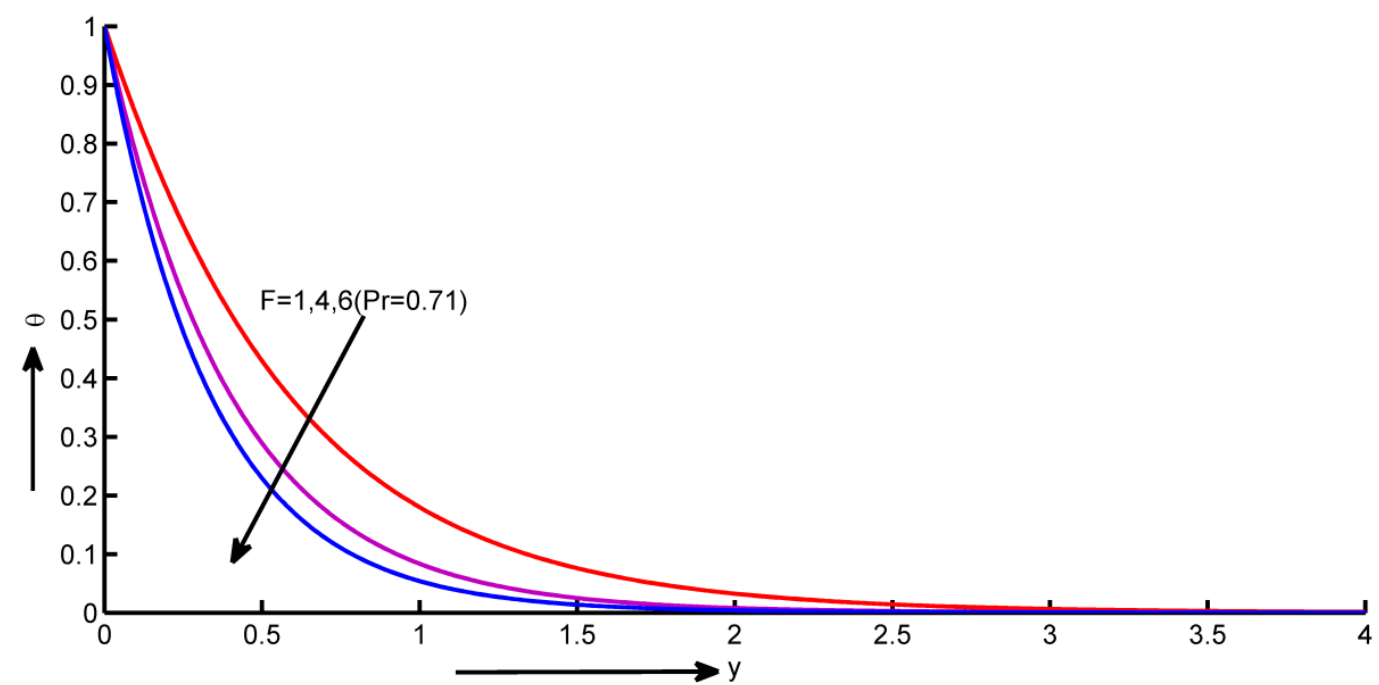

Fig. 14. Temperature profile for $\mathrm{Gr}=5.0\left(\mathrm{Gm}=5, \mathrm{~K}=1, \mathrm{M}=2, \mathrm{~K}_{0}=1, \mathrm{Q}=1, \mathrm{~S}_{0}=1\right.$ and $\left.\mathrm{Sc}=0.22\right)$

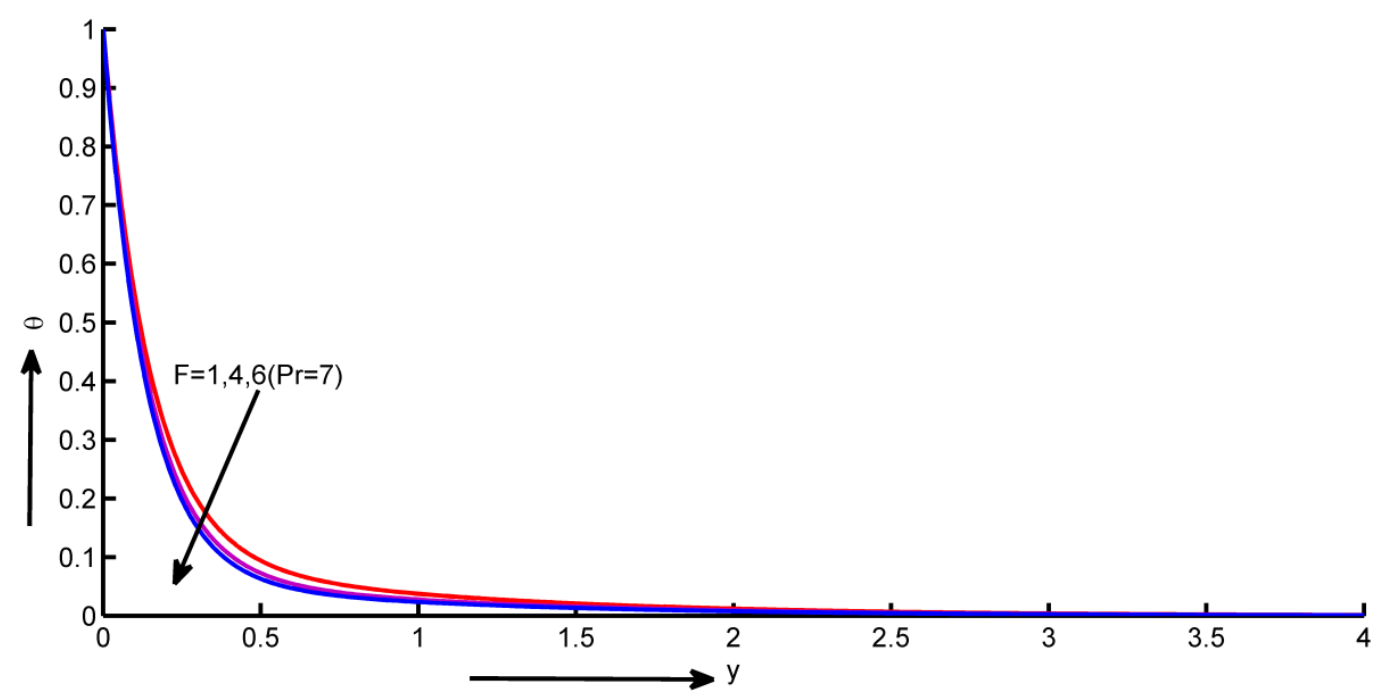

Fig. 15. Temperature profile for $\mathrm{Gr}=-5.0\left(\mathrm{Gm}=5, \mathrm{~K}=1, \mathrm{M}=2, \mathrm{~K}_{0}=1, \mathrm{Q}=1, \mathrm{~S}_{0}=1\right.$ and $\left.\mathrm{Sc}=0.22\right)$

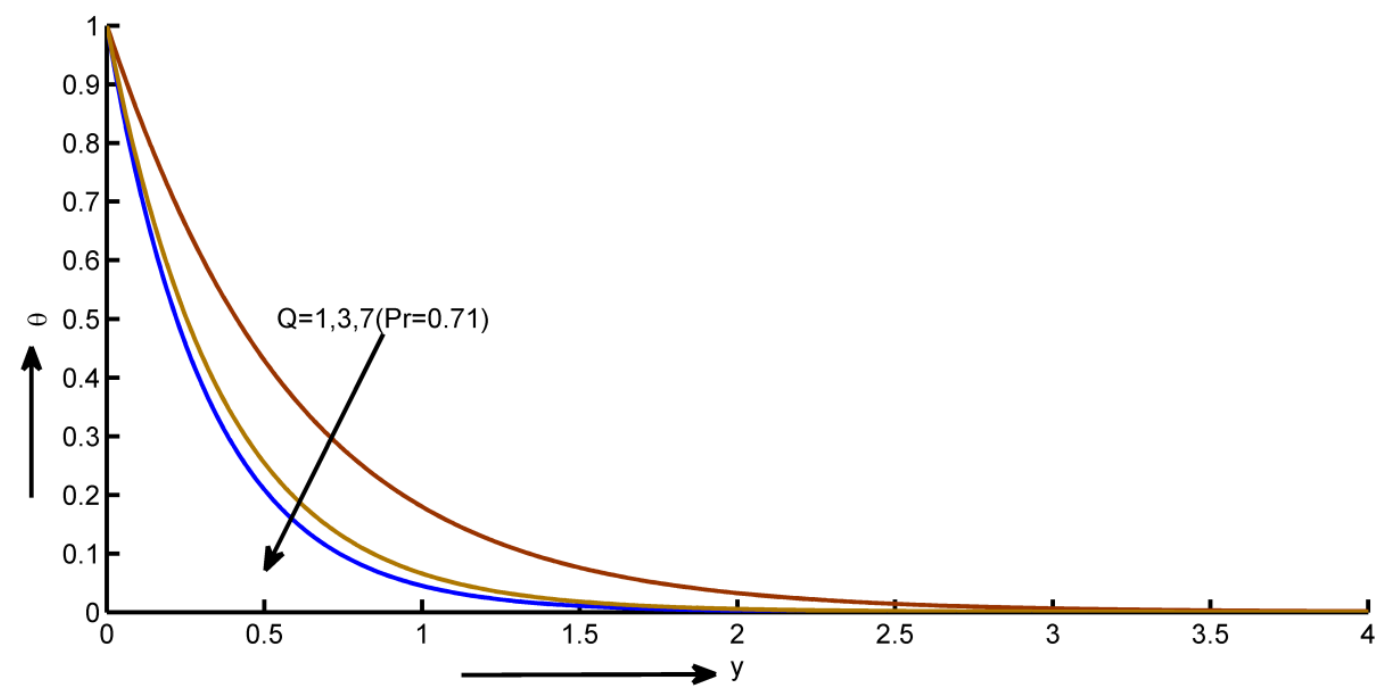

Fig. 16. Temperature profile for $\mathrm{Gr}=5.0\left(\mathrm{Gm}=5, \mathrm{~K}=1, \mathrm{M}=2, \mathrm{~K}_{0}=1, \mathrm{~F}=1, \mathrm{~S}_{0}=1\right.$ and $\left.\mathrm{Sc}=0.22\right)$ 


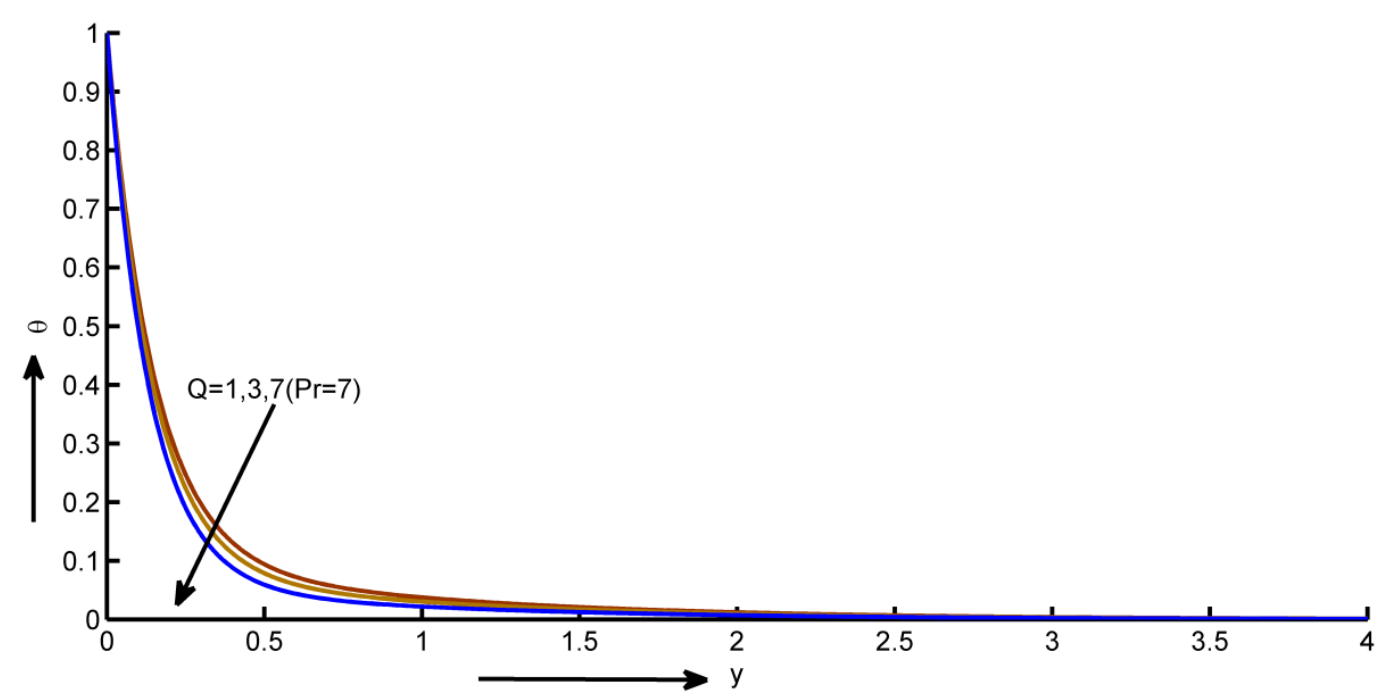

Fig. 17. Temperature profile for $\mathrm{Gr}=-5.0\left(\mathrm{Gm}=5, \mathrm{~K}=1, \mathrm{M}=2, \mathrm{~K}_{0}=1, \mathrm{Q}=1, \mathrm{~S}_{0}=1\right.$ and $\left.\mathrm{Sc}=0.22\right)$

Figure 18 to Figure 23 give the insight of species concentration curve for various values of $\mathrm{K}_{0}$, Sc and $\mathrm{S}_{0}$. It is to be noted that in the flow field the concentration falls steadily with $\mathrm{y}$ and it tends to zero as $y \rightarrow \infty$. A contrast assessment of curves in Figure 18 to Figure 23 depicts a decrease in concentration with an upsurge in chemical reaction parameter and Sc. Substantially, the increase of Sc means down fall of $D$ which results in the decrease of boundary layer of the concentration. Therefore, the concentration of the species is higher and lower for small and large values of Sc respectively and this is analogous to the increasing effects of the Prandt number on the thickness of boundary layer of temperature. The concentration fall level is due to the chemical reaction parameter and its increment values. For both (cooled and heated) plates, the concentration profile gets hiked due to So.

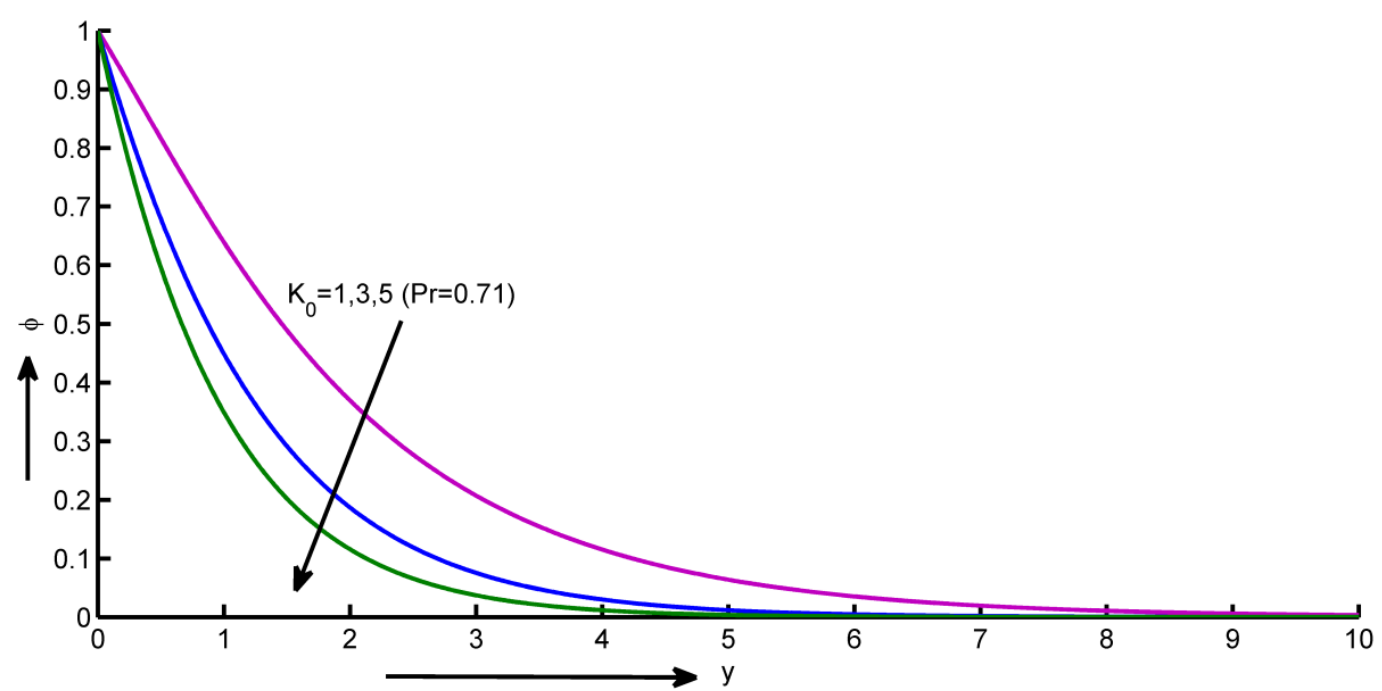

Fig. 18. Concentration profile for $\mathrm{Gr}=5.0\left(\mathrm{G} m=5, \mathrm{~K}=1, \mathrm{M}=2, \mathrm{Q}=1, \mathrm{~F}=1, \mathrm{~S}_{0}=1\right.$ and $\left.\mathrm{Sc}=0.22\right)$ 


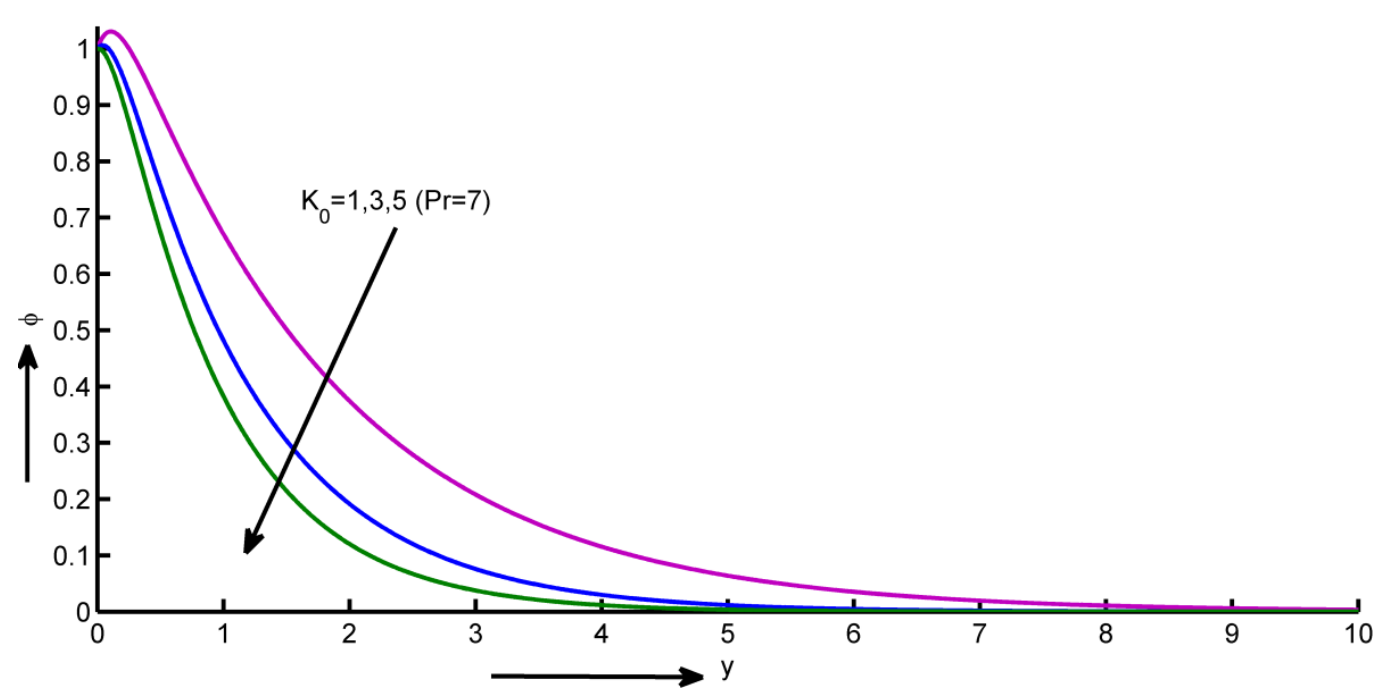

Fig. 19. Temperature profile for $\mathrm{Gr}=-5.0\left(\mathrm{Gm}=5, \mathrm{~K}=1, \mathrm{M}=2, \mathrm{Q}=1, \mathrm{~F}=1, \mathrm{~S}_{0}=1\right.$ and $\left.\mathrm{Sc}=0.22\right)$

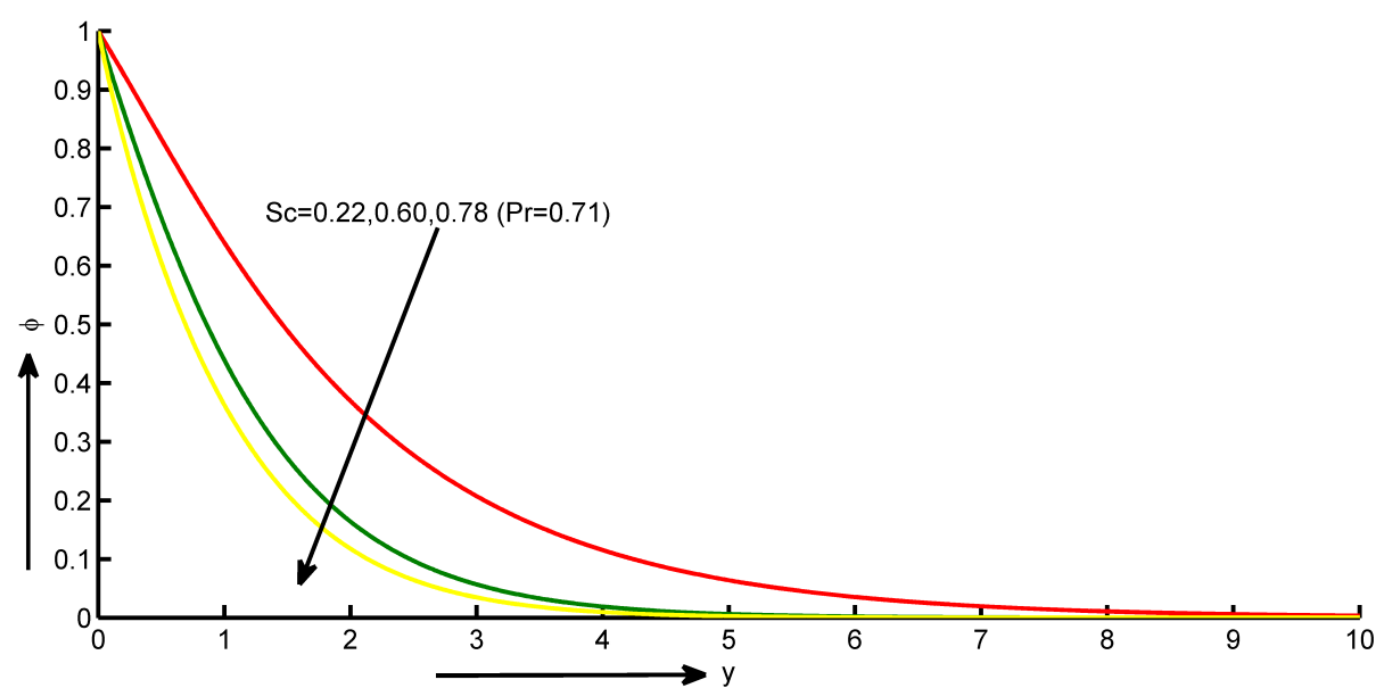

Fig. 20. Temperature profile for $\mathrm{Gr}=5.0\left(\mathrm{Gm}=5, \mathrm{~K}=1, \mathrm{M}=2, \mathrm{Q}=1, \mathrm{~F}=1, \mathrm{~S}_{0}=1\right.$ and $\left.\mathrm{K}_{0}=1\right)$

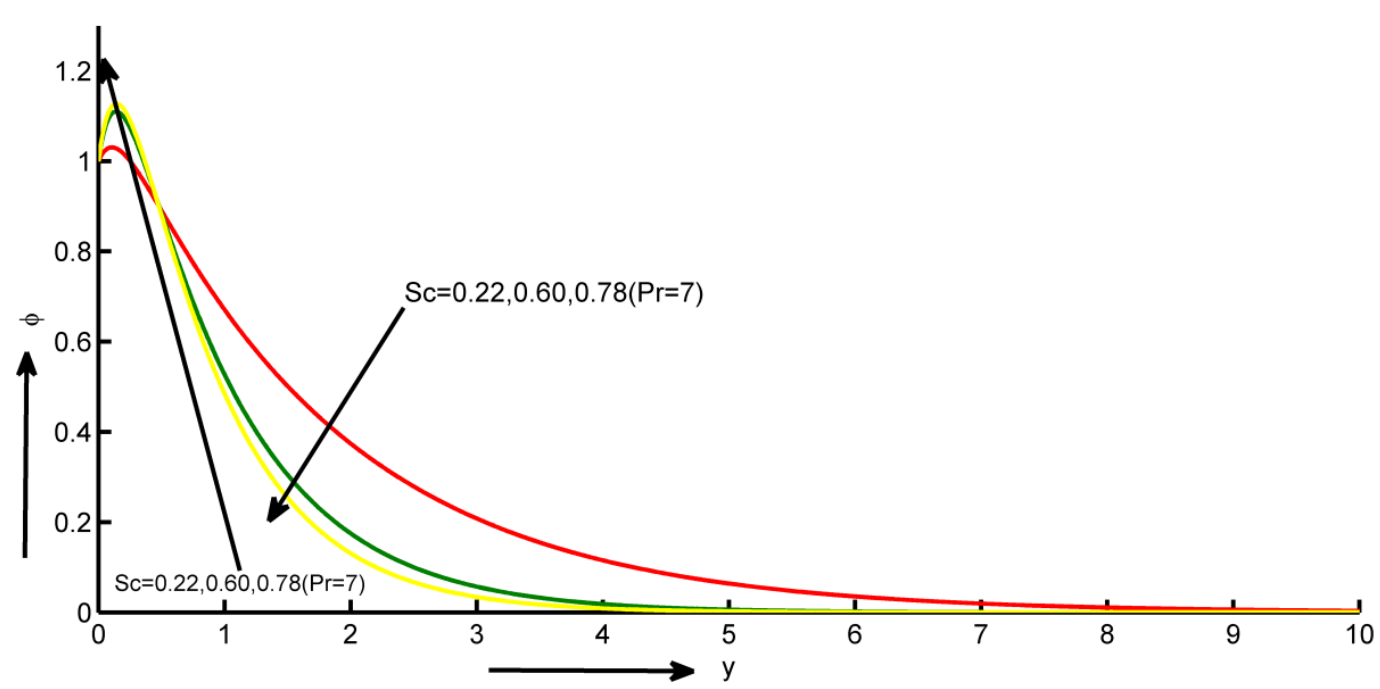

Fig. 21. Temperature profile for $\mathrm{Gr}=-5.0\left(\mathrm{Gm}=5, \mathrm{~K}=1, \mathrm{M}=2, \mathrm{Q}=1, \mathrm{~F}=1, \mathrm{~S}_{0}=1\right.$ and $\left.\mathrm{K}_{0}=1\right)$ 


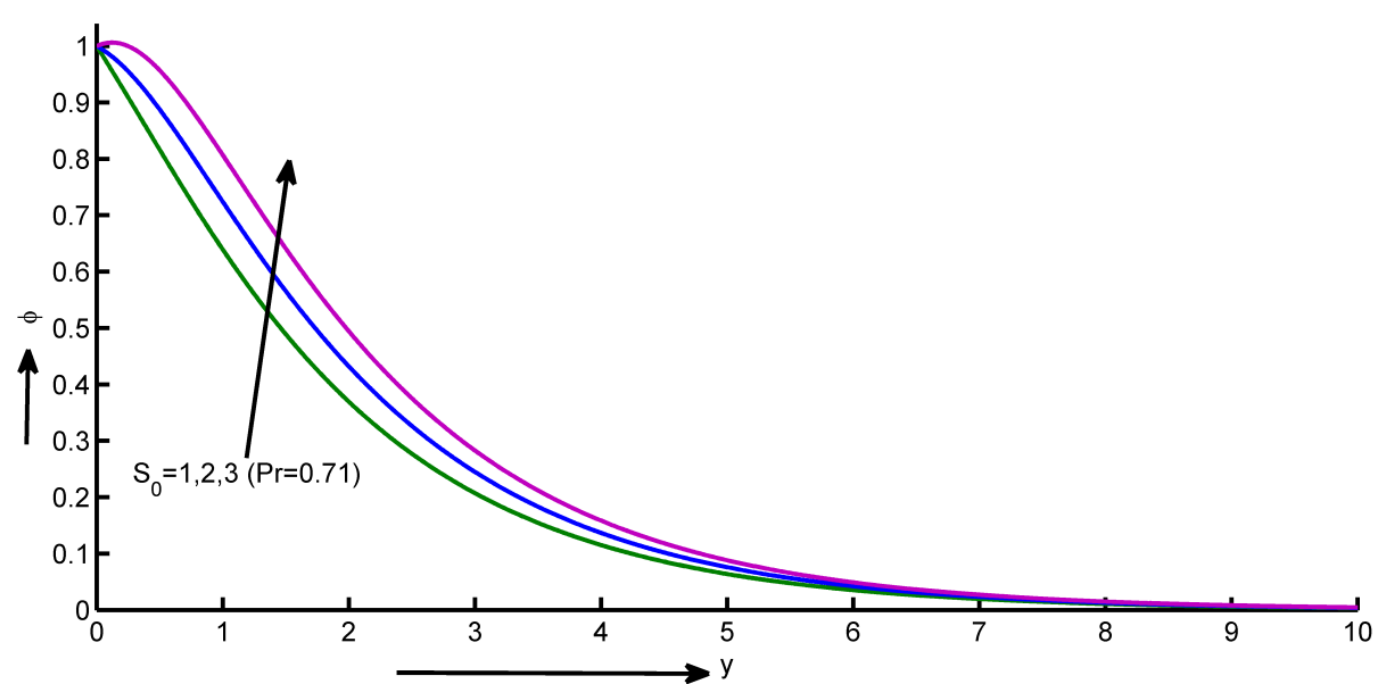

Fig. 22. Temperature profile for $\mathrm{Gr}=5.0\left(\mathrm{Gm}=5, \mathrm{~K}=1, \mathrm{M}=2, \mathrm{Q}=1, \mathrm{~F}=1, \mathrm{Sc}=0.22\right.$ and $\left.\mathrm{K}_{0}=1\right)$

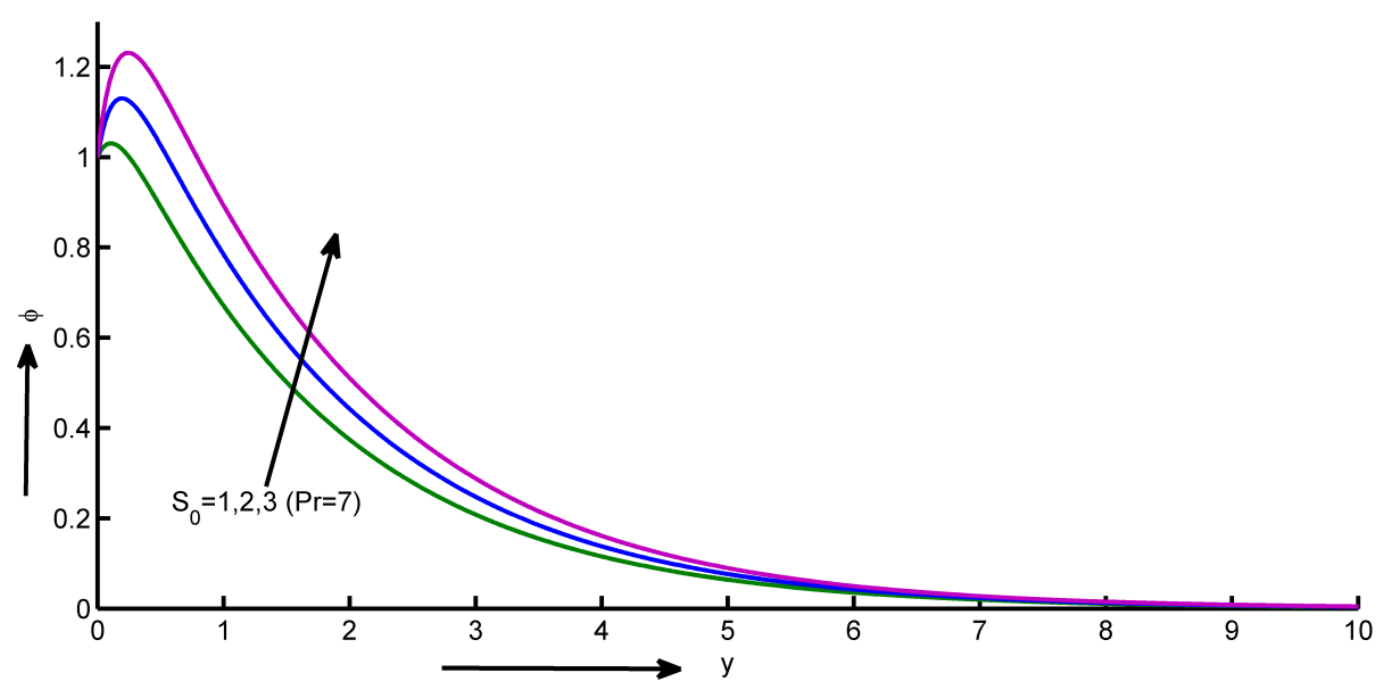

Fig. 23. Temperature profile for $\mathrm{Gr}=-5.0\left(\mathrm{Gm}=5, \mathrm{~K}=1, \mathrm{M}=2, \mathrm{Q}=1, \mathrm{~F}=1, \mathrm{Sc}=0.22\right.$ and $\left.\mathrm{K}_{0}=1\right)$

Table 1, Table 2 and Table 3 validates the influences of $M$, So, $K, G m, F, Q$ and $S c$ on skin friction, rate of heat and mass transfer respectively.

It is evident from Table 1 that an increasing value of $M$ decreases the effect of skin-friction for mercury, electrolytic solution, air and water for (cooled plate and heated) the plates. But an increase in $K$ and $G m$ enhances the skin-friction however rise in the values of $K$, diminishes the skin friction in only electrolytic solution.

In Table 2 rate of heat transfer and its variations are shown. It increases with the rising values of $F$ and $Q$. But in the case of the fluid flow on heated plate, Nu decreases with increase in $S_{0}$ for mercury, electrolytic solution, air, water and decreases for air, water.

The variations in rate of mass transfer are shown in Table 3. It increases with rising values of $K_{0}$ in both cooled and heated plates for fluids of mercury, electrolytic solution, air and water, but in the case of mercury, electrolytic solution, air, Sh increases with an increment in Sc but diminishes in the fluid for both plates. Similarly, increasing trend in $S_{0}$ for cooled plate is observed when the values of Sh falls in the fluid's mercury, electrolytic solution, air and water but in heated plate an opposite trend is noted for $S h$. 


\section{Table 1}

Variations in Skin friction

\begin{tabular}{|c|c|c|c|c|c|c|c|c|c|c|}
\hline \multirow[t]{3}{*}{$G m$} & \multirow[t]{3}{*}{$M$} & \multirow[t]{3}{*}{$K$} & \multicolumn{4}{|c|}{ Skin Friction $\tau(G r=5)$} & \multicolumn{4}{|c|}{ Skin Friction $\tau(G r=-5)$} \\
\hline & & & $\operatorname{Pr}=0.025$ & $\operatorname{Pr}=1.0$ & $\operatorname{Pr}=0.71$ & $\operatorname{Pr}=7$ & $\operatorname{Pr}=0.025$ & $\operatorname{Pr}=1.0$ & $\mathrm{Pr}=0.71$ & $\mathrm{Pr}=7$ \\
\hline & & & Mercury & $\begin{array}{l}\text { Electrolytic } \\
\text { solution }\end{array}$ & Air & Water & Mercury & $\begin{array}{l}\text { Electrolytic } \\
\text { solution }\end{array}$ & Air & Water \\
\hline 5 & & & 6.5075 & 6.3490 & 7.3516 & 5.6751 & 2.8328 & 2.9321 & 2.9802 & 4.1199 \\
\hline 10 & & & 10.4560 & 10.4235 & 12.1723 & 10.2210 & 6.7658 & 6.5525 & 6.7373 & 7.4989 \\
\hline 15 & & & 14.4038 & 14.5136 & 17.0227 & 14.7317 & 10.6878 & 9.8858 & 10.3002 & 10.1199 \\
\hline & 2 & & 6.5075 & 6.3490 & 7.3516 & 5.6751 & 2.8328 & 2.9321 & 2.9802 & 4.1199 \\
\hline & 3 & & 5.7299 & 5.5649 & 6.1709 & 4.9709 & 2.3762 & 2.5952 & 2.5430 & 3.5463 \\
\hline & 4 & & 5.1984 & 5.0447 & 5.4704 & 4.4962 & 2.0857 & 2.3078 & 2.2456 & 3.1664 \\
\hline & & 2 & 7.0617 & 7.0966 & 6.9600 & 6.2316 & 3.1751 & 2.5338 & 3.2115 & 4.4645 \\
\hline & & 3 & 7.2847 & 7.6694 & 7.2098 & 6.4633 & 3.3163 & 1.3869 & 3.2578 & 4.5953 \\
\hline & & 4 & 7.4052 & 8.2918 & 7.3516 & 6.5907 & 3.3933 & -0.3661 & 3.2610 & 4.6640 \\
\hline
\end{tabular}

Table 2

Variations in Nusselt Number

\begin{tabular}{|c|c|c|c|c|c|c|c|c|c|c|}
\hline \multirow[t]{3}{*}{ So } & \multirow[t]{3}{*}{$F$} & \multirow[t]{3}{*}{$Q$} & \multicolumn{4}{|c|}{ Nusselt Number Nu (Gr=5) } & \multicolumn{4}{|c|}{ Nusselt Number Nu (Gr= -5$)$} \\
\hline & & & $\operatorname{Pr}=0.025$ & $\operatorname{Pr}=1.0$ & $\operatorname{Pr}=0.71$ & $\operatorname{Pr}=7$ & $\operatorname{Pr}=0.025$ & $\operatorname{Pr}=1.0$ & $\operatorname{Pr}=0.71$ & $\operatorname{Pr}=7$ \\
\hline & & & Mercury & $\begin{array}{l}\text { Electrolytic } \\
\text { solution }\end{array}$ & Air & Water & Mercury & $\begin{array}{l}\text { Electrolytic } \\
\text { solution }\end{array}$ & Air & Water \\
\hline 1 & & & 1.4091 & 1.5740 & 1.6245 & 6.1734 & 1.4178 & 1.2624 & 1.5358 & 6.2551 \\
\hline 2 & & & 1.4098 & 1.6582 & 1.6152 & 5.7578 & 1.4141 & 0.9660 & 1.4241 & 5.8518 \\
\hline 3 & & & 1.4099 & 1.6925 & 1.6071 & 5.2751 & 1.4098 & 0.6197 & 1.2936 & 5.3814 \\
\hline & 4 & & 1.8510 & 2.6302 & 2.4460 & 6.7311 & 1.3445 & 2.5898 & 2.3204 & 6.8069 \\
\hline & 6 & & 2.6516 & 3.0822 & 2.9409 & 7.0466 & 2.6406 & 3.0984 & 2.9445 & 7.1191 \\
\hline & & 3 & 1.9850 & 2.2331 & 0.6403 & 6.5589 & 1.9746 & 1.9437 & -1.9104 & 6.6365 \\
\hline & & 5 & 2.4299 & 2.8740 & 2.7269 & 6.8932 & 2.3685 & 2.8768 & 2.7062 & 6.9673 \\
\hline & & 6 & 2.6516 & 3.0822 & 2.9409 & 7.0466 & 2.6406 & 3.0984 & 2.9445 & 7.1191 \\
\hline
\end{tabular}

Table 3

Variations in Sherwood Number

\begin{tabular}{|c|c|c|c|c|c|c|c|c|c|c|}
\hline \multirow[t]{3}{*}{ Sc } & \multirow[t]{3}{*}{$K_{0}$} & \multirow[t]{3}{*}{ So } & \multicolumn{4}{|c|}{ *Sherwood Number Sh (Gr=5) } & \multicolumn{4}{|c|}{ *Sherwood Number Sh (Gr= -5) } \\
\hline & & & $\operatorname{Pr}=0.025$ & $\operatorname{Pr}=1.0$ & $\operatorname{Pr}=0.71$ & $\operatorname{Pr}=7$ & $\operatorname{Pr}=0.025$ & $\operatorname{Pr}=1.0$ & $\operatorname{Pr}=0.71$ & $\operatorname{Pr}=7$ \\
\hline & & & Mercury & $\begin{array}{l}\text { Electrolytic } \\
\text { solution }\end{array}$ & Air & Water & Mercury & $\begin{array}{l}\text { Electrolytic } \\
\text { solution }\end{array}$ & Air & Water \\
\hline 0.22 & & & 0.4054 & 0.3667 & 0.3608 & -0.6481 & 0.4035 & 0.4338 & 0.3754 & -0.6661 \\
\hline 0.30 & & & 0.4959 & 0.4202 & 0.4265 & -0.9395 & 0.4943 & 0.5733 & 0.4695 & -0.9682 \\
\hline 0.60 & & & 0.9047 & 0.6327 & 0.7222 & -1.8236 & 0.9112 & 1.5080 & 1.0227 & -1.9234 \\
\hline & 0.5 & & 0.2469 & 0.2182 & 0.2080 & -0.7642 & 0.2447 & 0.2712 & 0.2154 & -0.7801 \\
\hline & 1.5 & & 0.5289 & 0.4830 & 0.4803 & -0.5474 & 0.5273 & 0.5605 & 0.5001 & -0.5670 \\
\hline & 3 & & 0.8116 & 0.7498 & 0.7542 & -0.2979 & 0.8106 & 0.8499 & 0.7850 & -0.3216 \\
\hline & & 2 & 0.2188 & 0.1046 & 0.1250 & -1.7067 & 0.2169 & 0.4041 & 0.2071 & -1.7481 \\
\hline & & 4 & -0.1539 & -0.4007 & -0.3128 & -3.1048 & -0.1502 & 0.8589 & 0.0633 & -3.2091 \\
\hline & & 6 & -0.5231 & -0.6650 & -0.6241 & -3.2517 & -0.5063 & 2.2155 & 0.2579 & -3.4406 \\
\hline
\end{tabular}

\section{Conclusion and Application}

In the presence of thermal diffusion, absorption and radiation, heat source or sink and chemical reactions, discussions on mixed MHD convection flow of heat as well as mass transfer past an infinite plate which is vertical and porous with effects of Ohmic heating and dissipation of viscosity in have been taken care of in this paper. The equations governed by the flow are firstly transformed to dimensionless form and are further elucidated using the perturbation method. The outcomes are 
depicted graphically for various range of values of the parameters that are considered during the examination of the problem. The present investigation can be summarized as follows:

- Velocity decreases with an increase value of $S c, M$ while it reverses effect values of $G m, K, S_{0}$ in both cooled and heated plates for fluids of air and water.

- Temperature falls with a rising values of $\operatorname{Pr}, F$, and $Q$ for both plates in air, water.

- Concentration decreases with enhancing values of $S c, K_{0}$ while it reverses effect of $S_{0}$ for both plates in air and water.

- Skin friction coefficient decreases with rising values of magnetic field parameter $(\mathrm{M})$ for both cooled and heated plate in mercury, electrolytic solution, air and water, while it reverses effect values of modified Grashof number $(\mathrm{Gm})$, permeability parameter $(\mathrm{K})$ in both cooled and heated plates for fluids are Air, Water, mercury and electrolytic solution.

- The rate of heat transfer of mercury, electrolytic solution, air and water, an increase with the rising values of heat absorption ( $Q$ ) and radiation parameter (F), for cooled and heated plate. But in the case of the fluid flow on heated plate, decreases with increase in Soret parameter (So) for mercury, electrolytic solution, air, water and also decreases for air, water and an increase for fluids mercury, electrolytic solution.

- The rate of mass transfer increases with rising values of chemical reaction parameter $\left(\mathrm{K}_{0}\right)$ in both cooled and heated plates for fluids of mercury, electrolytic solution, air and water.

- the rate of mass transfer increases in mercury, electrolytic solution, air and decreases in the fluid of Water for both plates when raising the values of Schmidt number (Sc). Similarly, enhancement of the values of Soret parameter $\left(S_{0}\right)$ for cooled plate, Sherwood number fall down in the fluid's mercury, electrolytic solution, air and water but in heated plate decrease for fluids mercury, water and increases in electrolytic solution air.

The consequences of the current study can be practically used in numerous chemical engineering process developments for example aeration, vaporization and condensation of substances, sublimation and crystal evolution along with the removal of thin films. Also, in several industrial applications they are being frequently used, e.g., polymer production, creation of ceramics or glassware and processing of foods.

The absolute presence of unadulterated air/water in nature is relatively not possible. The mixture of various foreign mass is certainly present either in air or water which sometimes causes the effect of Soret and Chemical effects. For example, ammonia, ethyl alcohol, benzene etc., react with air as soon as they interact under certain circumstances. The flow of air is caused by the water-vapor which is present in nature can be cited as one of biggest example. It is also triggered by the alterations in dilutions of material composition.

\section{References}

[1] Krishna Murthy, S. V. S. S. N. V. G., and Vinay Kumar. "MHD forces on double diffusive free convection process along a vertical wavy surface embedded in a doubly stratified fluid-saturated Darcy porous medium under the influence of Soret and Dufour effect." European Journal of Computational Mechanics 27, no. 1 (2018): 33-57. https://doi.org/10.1080/17797179.2018.1439150

[2] Umamaheswar, M., S. V. K. Varma, and C. Sucharitha. "MHD double diffusive and chemically reactive fluid flow through a rotating porous plate." International Journal of Research-Granthaalayah 5, no. 7 (2017): $363-373$. https://doi.org/10.29121/granthaalayah.v5.i7.2017.2143

[3] Seth, G. S., S. Sarkar, and A. K. Singha. "Capturing the transient behaviour of MHD double-diffusive free convection in vertical channel with adiabatic and isothermal walls and mass inflow at adiabatic wall." In Applications of Fluid Dynamics, pp. 397-409. Springer, Singapore, 2018. https://doi.org/10.1007/978-981-10-5329-0 29 
[4] Raju, V., K. Hemalatha, and V. Srihari Babu. "MHD Viscoelastic Fluid Flow Past an Infinite Vertical Plate in the Presence of Radiation and Chemical Reaction." International Journal of Applied Engineering Research 14, no. 5 (2019): 1062-1069.

[5] Reddy, Singamala Harinath, M. Umamaheswar, P. Chandra Reddy, M. C. Raju, and E. Keshava Reddy. "MHD double diffusive convective flow of heat generating fluid in the presence of Soret effect." In AIP Conference Proceedings, vol. 2246, no. 1, p. 020073. AIP Publishing LLC, 2020. https://doi.org/10.1063/5.0014623

[6] Chandra Reddy, P., K. Venkateswara Raju, M. Umamaheswar, and M. C. Raju. "Buoyancy Effects on Chemically Reactive Magnetonanofluid Past a Moving Vertical Plate." Bulletin of Pure and Applied Sciences 38E, no. 1 (2019): 193-207. https://doi.org/10.5958/2320-3226.2019.00017.1

[7] Agarwalla, Suman, and Nazibuddin Ahmed. "MHD mass transfer flow past an inclined plate with variable temperature and plate velocity embedded in a porous medium." Heat Transfer-Asian Research 47, no. 1 (2018): 27-41. https://doi.org/10.1002/htj.21288

[8] Bhargavi, D., and J. Sharath Kumar Reddy. "Analytical study of forced convection in a channel partially filled with porous material with effect of magnetic field: constant wall heat flux." Special Topics \& Reviews in Porous Media: An International Journal 9, no. 3 (2018): 201-216. https://doi.org/10.1615/SpecialTopicsRevPorousMedia.v9.i3.10

[9] Sheikholeslami, M., Zhixiong Li, and Ahmad Shafee. "Lorentz forces effect on NEPCM heat transfer during solidification in a porous energy storage system." International Journal of Heat and Mass Transfer 127 (2018): 665674. https://doi.org/10.1016/j.ijheatmasstransfer.2018.06.087

[10] Sharma, Kalpna, and Sumit Gupta. "Radiation effects on MHD boundary layer flow and heat transfer along a stretching cylinder with variable thermal conductivity in a porous medium." Journal of Porous Media 21, no. 8 (2018): 763-779. https://doi.org/10.1615/JPorMedia.2018019284

[11] Kumar, T. Sravan, and B. Rushi Kumar. "Magnetohydrodynamic Nanofluid flow and heat transfer over a stretching sheet." Special Topics \& Reviews in Porous Media: An International Journal 9, no. 4 (2018): 365-378. https://doi.org/10.1615/SpecialTopicsRevPorousMedia.2018022792

[12] Kalapana, M., and R. Bhuvana Vijaya. "Mass transfer on MHD convection flow past an infinite vertical porous plate." In AIP Conference Proceedings, vol. 2246, no. 1, p. 020078. AIP Publishing LLC, 2020. https://doi.org/10.1063/5.0014634

[13] Obulesu, M., K. Raghunath, and R. Sivaprasad. "Hall current effects on MHD convective flow past a porous plate with thermal radiation, chemical reaction with radiation absorption." In AIP Conference Proceedings, vol. 2246 , no. 1, p. 020003. AIP Publishing LLC, 2020. https://doi.org/10.1063/5.0014423

[14] Raghunath, K., M. Obulesu, and Dr R. Siva Prasad. "Heat and mass transfer on Unsteady MHD flow of through porous medium between two vertical porous plates." In AIP Conference Proceedings, vol. 2220, pp. 130003-1. AIP Publishing LLC, 2020. https://doi.org/10.1063/5.0001103

[15] Obulesu, M., and R. Sivaprasad. "MHD double diffusive visco-elastic fluid flow past an infinite vertical porous plate under the influence of radiation absorption." In AIP Conference Proceedings, vol. 2246, no. 1, p. 020069. AIP Publishing LLC, 2020. https://doi.org/10.1063/5.0014428

[16] Raghunath, K., M. Obulesu, and A. Shareef. "MHD Flow of Second Grade Fluid over an Infinite Permeable Plate Embedded in a Porous Medium." Journal of Xi'an University of Architecture \& Technology 12, no. 2 (2020): 645655.

[17] Obulesu, Mopuri, and Racharla Siva Prasad. "Hall current effects on MHD convective flow past a porous plate with thermal radiation, chemical reaction with thermophoresis." Annals of the Faculty of Engineering Hunedoara 18 , no. 3 (2020): 205-212. https://doi.org/10.1063/5.0014423

[18] Reddy, N. Ananda, S. V. K. Varma, and M. C. Raju. "Thermo diffusion and chemical effects with simultaneous thermal and mass diffusion in MHD mixed convection flow with ohmic heating." Journal of Naval Architecture and Marine Engineering 6, no. 2 (2009): 84-93. https://doi.org/10.3329/iname.v6i2.3761

[19] Cogley, Allen C., Walter G. Vincent, and Scott E. Gilles. "Differential approximation for radiative transfer in a nongrey gas near equilibrium." AIAA Journal 6, no. 3 (1968): 551-553. https://doi.org/10.2514/3.4538

[20] Kumar, G. Charan, Konda Jayarami Reddy, Rama Krishna Konijeti, and M. Narendradh Reddy. "Non-uniform heat source/sink and joule heating effects on chemically radiative MHD mixed convective flow of micropolar fluid over a stretching sheet in porous medium." In Defect and Diffusion Forum, vol. 388, pp. 281-302. Trans Tech Publications Ltd, 2018. https://doi.org/10.4028/www.scientific.net/DDF.388.281

[21] Rao, Abburi Sreenivasa, Peddi Phani Bushan Rao, and Charan Kumar Ganteda. "Magnetohydrodynamic Williamson fluid motion over an exponentially stretching sheet with chemically radiative heat source effects under suction/injection." Journal of Mathematical and Computational Science 10, no. 6 (2020): 2634-2657.

[22] Vedavathi, N., G. Dharmaiah, K. S. Balamurugan, and G. Charan Kumar. "Chemical reaction, radiation and dufour effects on casson magneto hydro dynamics fluid flow over a vertical plate with heat source/sink." Global Journal of Pure and Applied Mathematics 12, no. 1 (2016): 191-200. 
[23] Krishnarao, B. Venkata, Jayaramireddy Konda, and G. Charankumar. "MHD and Thermal Radiation Effects of a Nanofluid over a Stretching Sheet using HAM." International Journal of Recent Technology and Engineering 8, no, 4 (2019): 3489-3496. https://doi.org/10.35940/ijrte.C6726.118419

[24] Rao, Abburi Sreenivasa, Peddi Phani Bushan Rao, and Charan Kumar Ganteda. "Influence of heat source effect on MHD flow of casson fluid over a nonlinearly stretching sheet with chemical reaction and slip conditions." International Journal of Mechanical and Production Engineering Research and Development 10, no. 2 (2020): 15111528.

[25] Goud, B. Shankar, Y. Dharmendar Reddy, and V. Srinivasa Rao. "Thermal radiation and Joule heating effects on a magnetohydrodynamic Casson nanofluid flow in the presence of chemical reaction through a non-linear inclined porous stretching sheet." Journal of Naval Architecture and Marine Engineering 17, no. 2 (2020): 143-164. https://doi.org/10.3329/iname.v17i2.49978

[26] Kumar, M. Anil, Y. Dharmendar Reddy, V. Srinivasa Rao, and B. Shankar Goud. "Thermal radiation impact on MHD heat transfer natural convective nano fluid flow over an impulsively started vertical plate." Case Studies in Thermal Engineering 24 (2021): 100826. https://doi.org/10.1016/i.csite.2020.100826

[27] Goud, B. Shankar, Pudhari Srilatha, P. Bindu, and Y. Hari Krishna. "Radiation effect on MHD boundary layer flow due to an exponentially stretching sheet." Advances in Mathematics: Scientific Journal 9, no. 12 (2020): 1075510761. https://doi.org/10.37418/amsj.9.12.59

[28] Goud, B. Shankar, J. Venkata Madhu, and MN Raja Shekar. "MHD viscous dissipative fluid flows in a channel with a stretching and porous plate with radiation effect." International Journal of Innovative Technology and Exploring Engineering 8, no. 11 (2019). https://doi.org/10.35940/ijitee.K2086.0981119 